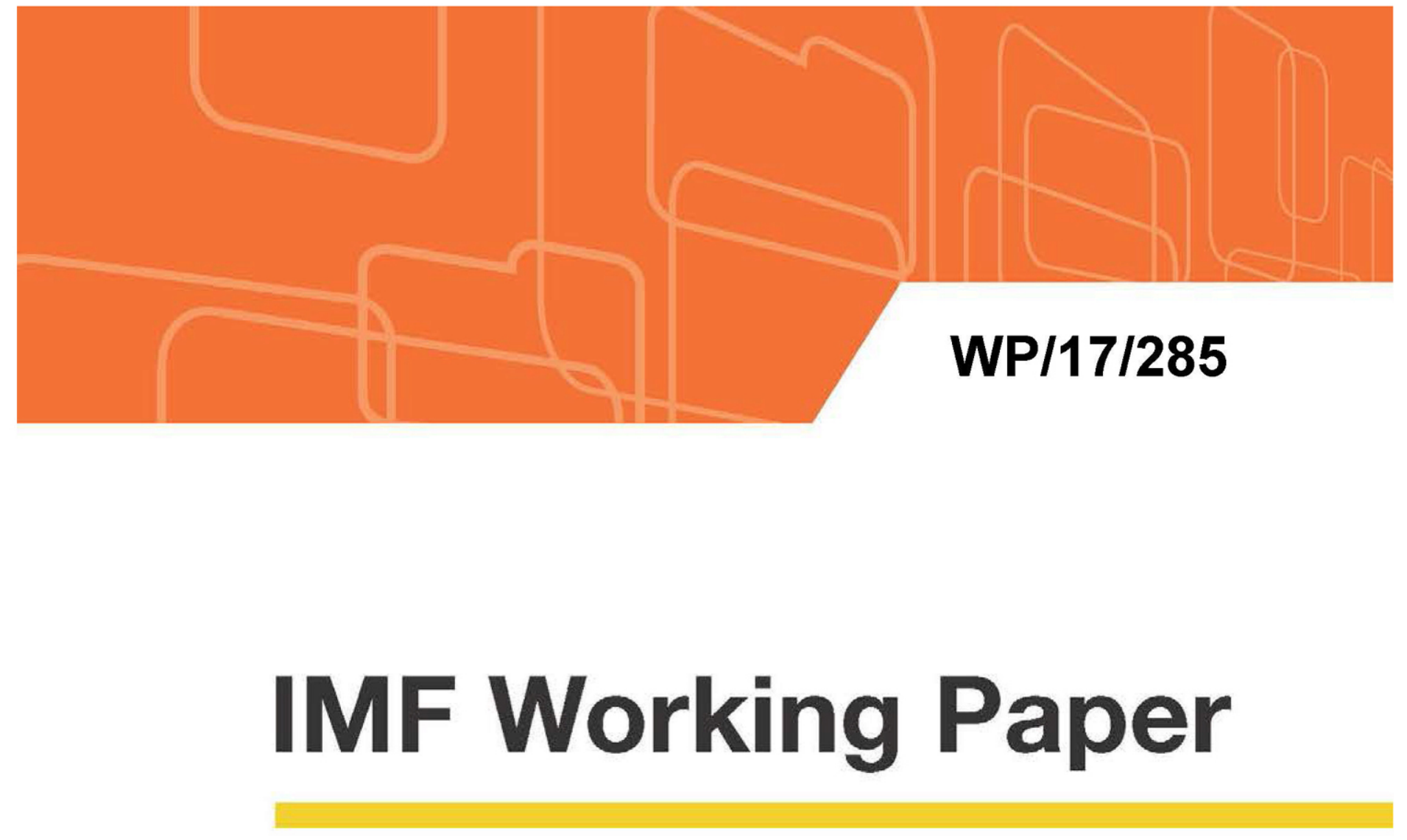

\title{
Shadow Banking and Market Discipline on Traditional Banks
}

by Anil Ari, Matthieu Darracq-Paries, Christoffer Kok \& Dawid Żochowski

IMF Working Papers describe research in progress by the author(s) and are published to elicit comments and to encourage debate. The views expressed in IMF Working Papers are those of the author(s) and do not necessarily represent the views of the IMF, its Executive Board, or IMF management.

$$
\text { I N T E R N A T I O N A L M O N E T A R Y F U N D }
$$




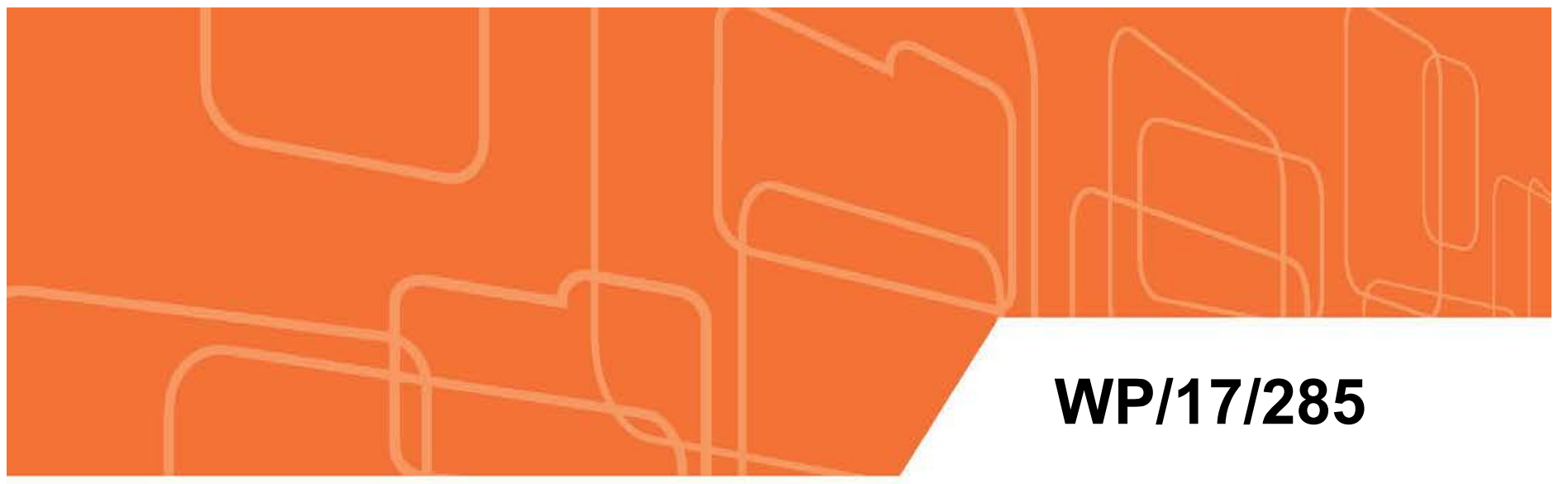

\section{IMF Working Paper}

\section{Shadow Banking and Market Discipline on Traditional Banks}

by Anil Ari, Matthieu Darracq-Paries, Christoffer Kok \& Dawid Żochowski

IMF Working Papers describe research in progress by the author(s) and are published to elicit comments and to encourage debate. The views expressed in IMF Working Papers are those of the author(s) and do not necessarily represent the views of the IMF, its Executive Board, or IMF management. 


\title{
IMF Working Paper
}

Research Department

Shadow Banking and Market Discipline on Traditional Banks ${ }^{1}$

Prepared by Anil Ari, Matthieu Darracq-Paries, Christoffer Kok \& Dawid Żochowski

Authorized for distribution by Maria Soledad Martinez Peria

December 2017

\begin{abstract}
IMF Working Papers describe research in progress by the author(s) and are published to elicit comments and to encourage debate. The views expressed in IMF Working Papers are those of the author(s) and do not necessarily represent the views of the IMF, its Executive Board, or IMF management.
\end{abstract}

\begin{abstract}
We present a model in which shadow banking arises endogenously and undermines market discipline on traditional banks. Depositors' ability to re-optimize in response to crises imposes market discipline on traditional banks: these banks optimally commit to a safe portfolio strategy to prevent early withdrawals. With costly commitment, shadow banking emerges as an alternative banking strategy that combines high risk-taking with early liquidation in times of crisis. We bring the model to bear on the 2008 financial crisis in the United States, during which shadow banks experienced a sudden dry-up of funding and liquidated their assets. We derive an equilibrium in which the shadow banking sector expands to a size where its liquidation causes a fire-sale and exposes traditional banks to liquidity risk. Higher deposit rates in compensation for liquidity risk also weaken threats of early withdrawal and traditional banks pursue risky portfolios that may leave them in default. Policy interventions aimed at making traditional banks safer such as liquidity support, bank regulation and deposit insurance fuel further expansion of shadow banking but have a net positive impact on financial stability. Financial stability can also be achieved with a tax on shadow bank profits.
\end{abstract}

JEL Classification Numbers: E44, E58, G01, G21, G23, G28

Keywords: Shadow banking, Financial crisis, Market discipline, Fire-sales

Author's E-Mail Address: aari@imf.org, matthieu.darracq_paries@ecb.int, christoffer.kok@ecb.int, dawid.zochowski@ecb.int

\footnotetext{
${ }^{1}$ An earlier version of this paper was circulated as ECB Working Paper No. 1943 under the title "When Shadows Grow Longer: Shadow banking with endogenous entry." We would like to thank for helpful comments to Giancarlo Corsetti, Chryssi Giannitsarou, Deniz Igan, Anil Kashyap, Paul Schempp, an anonymous referee, and seminar participants at the University of Cambridge, the European Central Bank, RES 2017, IFABS 2017, the 14th Macroeconomic Policy Research Workshop on Macroprudential Policy and MMF 2017. The views expressed herein are those of the authors and do not necessarily represent those of the International Monetary Fund or the European Central Bank. All errors are our own.
} 


\section{Contents}

1 Introduction $\quad \underline{5}$

2 Motivating evidence $\quad \underline{8}$

3 A simple model $\quad \underline{13}$

3.1 Agents and their optimal strategies . . . . . . . . . . . . . . 15

3.1.1 Entrepreneurs ..................... 15

3.1.2 Secondary market and outside investors . . . . . . . . . . . . . . . 17

3.1.3 Households ........................ . . . 18

3.1 .4 Banks ............................... 20

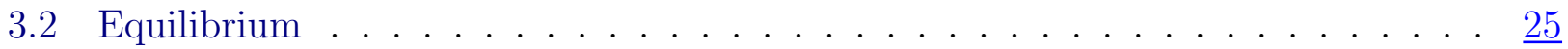

3.2.1 Fire-sales and bank strategies . . . . . . . . . . . 25

3.2 .2 Interior equilibrium . . . . . . . . . . . . . . . . . 26

4 A model with liquidity risk $\quad \underline{28}$

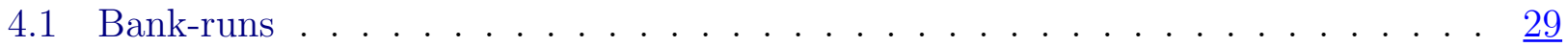

4.2 Secondary market . . . . . . . . . . . . . . . . . . . $\underline{30}$

4.3 Analytical results . . . . . . . . . . . . . . . . . . . 31

5 Numerical results $\quad \underline{32}$

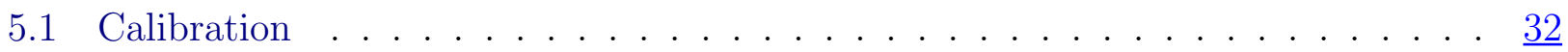

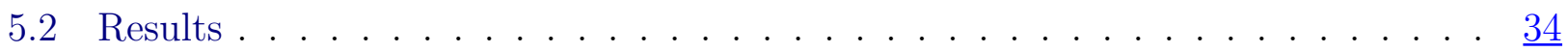

6 Policy analysis $\quad \underline{36}$

6.1 Asset purchases . . . . . . . . . . . . . . . . . . $\underline{36}$

6.2 Interventions to secure traditional banks . . . . . . . . . . . . . . . $\underline{38}$

6.3 Tax on shadow bank profits . . . . . . . . . . . . . . . . . $\underline{40}$

7 Conclusion $\quad \underline{41}$

8 Appendix $\quad \underline{44}$

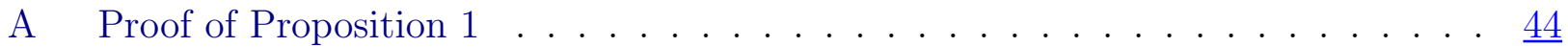

B Limited liability . . . . . . . . . . . . . . . . . . $\underline{45}$

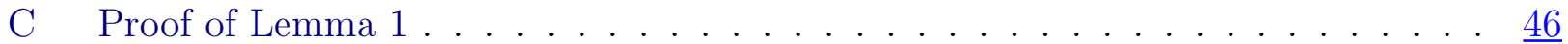

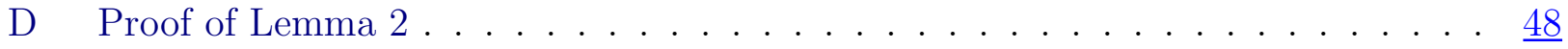

D.1 Case 1 .............................. 48

D.2 Case $2 \ldots \ldots \ldots \ldots \ldots \ldots$

D.3 Case $3 \ldots \ldots \ldots \ldots \ldots \ldots$ 


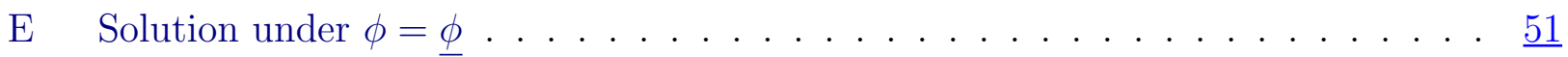

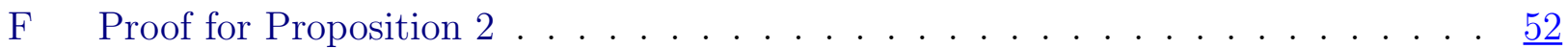

F.1 Proof for condition (46) $\ldots \ldots \ldots \ldots \ldots \ldots$

F.2 Proof for condition (47) $\ldots \ldots \ldots \ldots \ldots \ldots \ldots$

F.3 Proof for condition (48) $\ldots \ldots \ldots \ldots \ldots \ldots \ldots \ldots \ldots$

F.4 Proof for condition (49) $\ldots \ldots \ldots \ldots \ldots \ldots \ldots$

F.5 Proof for the non-emptiness of $(\underline{\tau}, \bar{\tau}) \ldots \ldots \ldots \ldots \underline{56}$

G Proof for Proposition $3 \ldots \ldots \ldots \ldots \ldots \ldots$

$\mathrm{H}$ Example fire-sale function . . . . . . . . . . . . . . . . 59

I Description of the model with liquidity risk . . . . . . . . . . . . $\underline{59}$

I.1 Entrepreneurs . . . . . . . . . . . . . . . . . . . . . $\underline{60}$

I.2 Banks . . . . . . . . . . . . . . . . . . . . . . $6 \underline{60}$

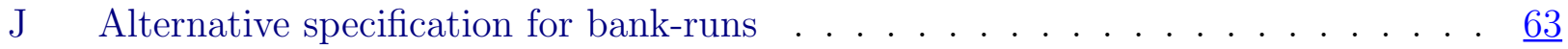




\section{Introduction}

Recent decades have seen rapid growth in financial intermediation by non-bank entities based on a business model that combines highly-leveraged, short-term funding with risky long-term investments such as sub-prime mortgage lending. In the 2008 financial crisis, these "shadow banks" experienced a sudden dry-up in their funding and liquidated their assets. The ensuing turmoil quickly spread to traditional commercial banks which reduced their credit to the private sector. This has contributed to the deepest recession since the Great Depression, raising two important questions. ${ }^{1}$ First, what circumstances and mechanisms lead to the emergence and expansion of shadow banking? Second, how does shadow banking affect the portfolio and funding strategies of traditional banks?

In this paper, we propose a framework where depositors may withdraw their deposits early in reaction to crises. ${ }^{2}$ These "early withdrawals" constitute an optimal response to adverse changes in banks' solvency prospects and become a source of market discipline: traditional banks optimally commit to a safe portfolio strategy to prevent early withdrawals. When commitment is costly, shadow banking emerges as an alternative banking strategy that combines a risky portfolio strategy with early withdrawals in times of crisis. To the best of our knowledge, this paper presents the first model where shadow and traditional banks coexist and interact without regulatory arbitrage or direct contractual linkages.

We bring this theoretical model to bear on the 2008 financial crisis, its transmission to the traditional banking sector, and policy debates on shadow banking and interventions in support of banks. In doing so, we account for two key empirical facts: Shadow banks faced a sudden contraction in funding and the liquidation of their assets caused a fire-sale. Traditional banks did not suffer from withdrawals, experienced a sharp rise in their funding costs, and re-allocated their portfolios towards safe and liquid assets.

We develop our analysis by specifying a closed economy model with households, entrepreneurs, outside investors, and a banking sector. Banks collect deposits from households and choose their portfolios of safe, risky, and liquid assets; households lend to banks on terms that depend on their solvency prospects; entrepreneurs originate assets. ${ }^{3}$ Following news signals that revise expected asset returns, households decide whether to withdraw their deposits early and banks trade assets with outside investors in a secondary market with cash-in-the-market pricing (Allen

\footnotetext{
${ }^{1}$ See Brunnermeier (2009) for an in-depth analysis of the financial crisis and its channels of transmission. For detailed descriptions of shadow banking activities, see Adrian and Ashcraft (2012) and Pozsar et al. (2013).

${ }^{2}$ Early withdrawals are distinct from self-fulfilling bank-runs à la Diamond and Dybvig (1983). For an early withdrawal to take place, depositors must find it optimal to withdraw their funds even when no other depositor does so.

${ }^{3}$ There is no deposit insurance in the baseline model but we consider its impact as part of policy analysis. In this context, the baseline model can be interpreted as an analysis of market discipline arising from nondepository bank liabilities or a counterfactual exercise in which shadow banking emerges even without any opportunities for regulatory arbitrage.
} 
and Gale, 1994, 2005).

A key element in the model is the equilibrium relationship between secondary market prices and bank strategies. During early withdrawals, shadow banks liquidate their assets in the secondary market to repay their depositors. Fire-sale externalities then create strategic substitutabilities in banks' decision to pursue a shadow banking strategy: As the shadow banking sector grows larger, its liquidation causes a deeper fire-sale, reducing the payoff from shadow banking relative to traditional banking, and bringing about an interior equilibrium where shadow and traditional banks coexist.

Analyzing the effects of fire-sales on market discipline yields important insights for vulnerability to financial crises. The key intuition is that low deposit rates strengthen early withdrawal incentives as depositors stand to lose less in terms of interest foregone. Therefore, market discipline on traditional banks is strong whenever deposit rates are low. This is precisely the case when there are no fire-sales: Interest rates on deposits are low and market discipline drives traditional banks to commit to a safe portfolio strategy. With the prospect of a fire-sale, on the other hand, depositors demand higher rates in compensation for liquidity risk. ${ }^{4}$ This weakens early withdrawal incentives and allows traditional banks to pursue risky portfolios that may leave them in default. In equilibrium, the shadow banking sector expands to a size where its liquidation causes a fire-sale and undermines market discipline through this mechanism.

The model provides novel and important insights for policy design. By the above mechanism, taxation of shadow bank activities is conducive to financial stability. These interventions deter banks from pursuing a shadow banking strategy and can be used to prevent the shadow banking sector from reaching a size where it causes a fire-sale.

We also show that outcomes from policy interventions differ substantially when adjustments in the size of the shadow banking sector are taken into account. For example, asset purchases in the secondary market are effective in alleviating fire-sales at a given shadow bank sector size. However, the ex-ante anticipation of asset purchases fuels further growth of the sector and renders the intervention completely ineffective. This troubles policymakers with time inconsistency issues: once the fire-sale is underway, they find it tempting to intervene.

Policy interventions in support of traditional banks also lead to an expansion in shadow banking but contribute to financial stability. Specifically, we show that collateralized liquidity provision secures traditional banks from liquidity risk and restores market discipline. Deposit insurance guarantees also eliminate liquidity risk but necessitate the replacement of market discipline with bank regulation. These two measures - collateralized liquidity provision and

\footnotetext{
${ }^{4}$ What is important for this mechanism is that illiquidity leads to expected losses for depositors. To achieve this, we posit that illiquid banks are vulnerable to self-fulfilling runs (which are distinct from early withdrawawls). Another way to attain the same outcome would be to introduce idiosyncratic liquidity needs to assets held by banks. For example, a portion of bank assets may be backed by projects that fail without the input of additional funds.
} 
deposit insurance combined with regulatory constraints - have the exact same outcome: they stabilize the traditional banking sector, but in doing so diminish the fire-sale and expand the shadow banking sector. We find that the former effect outweighs the latter so that the net impact on financial stability is positive.

We build upon a growing literature that provides micro-foundations for the existence and growth of shadow banking. The rapid growth of shadow banking in recent decades is well documented (see e.g. Claessens et al., 2012; Pozsar et al., 2013). Gennaioli et al. (2013) emphasize the ability of shadow banks to generate safe assets through securitization. They show that shadow banks become excessively exposed to systemic risk when low probability tail events are neglected by investors. In a similar vein, Moreira and Savov (2017) focus on liquidity transformation whereby shadow banks create money-like assets that become illiquid in times of high uncertainty. Harris et al. (2014), Plantin (2015) and Ordoñez (2017) highlight the role of regulatory arbitrage as a primary cause of shadow banking. In these studies, regulatory constraints restrict intermediation by traditional banks and create opportunities for unregulated shadow banks.

Our contribution to this literature is to show that shadow banking may arise as an equilibrium outcome without any advantages in intermediation technologies or opportunities for regulatory arbitrage. We assume, realistically, that commitment is costly and show that exante identical banks endogenously cluster into traditional and shadow banking strategies, where the former optimally pay a lump-sum cost to commit to a safe portfolio strategy. In this context, commitment costs reflect any costly action undertaken by banks to resolve asymmetric information issues with their depositors, such as providing detailed balance sheet reports, eschewing opaque intermediation processes like securitization, or issuing costly equity with voting rights.

This paper is also related to a recent strand of literature that analyses interactions between traditional and shadow banks. Gornicka (2016) considers traditional banks' incentives to gain off-balance sheet exposure by extending implicit guarantees to shadow banks. Hanson et al. (2015) present a framework where shadow and traditional banks have access to a common pool of liquidity. They show that traditional banks have a comparative advantage in holding illiquid assets with low fundamental risk when they are protected by deposit insurance guarantees. In a similar environment, Luck and Schempp (2016) find that shadow banking grows excessively large from a social viewpoint due to pecuniary externalities similar to the fire-sale externalities considered here.

We contribute to this literature by deriving an equilibrium where shadow and traditional banks coexist and interact without regulatory arbitrage or (implicit) contractual linkages. By doing this, we provide novel insights about how shadow banking affects market discipline on traditional banks. We also establish a free market benchmark to compare bank regulation and 
other policy interventions against.

Our modelling choices draw heavily from observations on the 2008 financial crisis. Acharya et al. (2013) document the collapse in the market for asset-backed commercial papers at the onset of the crisis while Gorton and Metrick (2012) and Krishnamurty et al. (2014) show a similar contraction in repo markets. Together, these two markets accounted for the vast majority of funding for shadow banks. Covitz et al. (2013) find that the dry-up in funding for shadow banks was associated with a rise in macro-financial risks such as uncertainty about sub-prime mortgages values. In our model, the definitive characteristic of the shadow banking strategy is its vulnerability to early withdrawals that closely resemble these events. Consistent with Covitz et al. (2013), early withdrawals are triggered by a negative revision in expected asset payoffs.

We propose that fire-sales caused by the liquidation of shadow banks play a key role in the spread of financial instability to traditional banks. Shleifer and Vishny (2011) provide an extensive review of the literature on fire-sales while Krishnamurthy (2010), Merrill et al. (2012), and Mitchell and Pulvino (2012) provide empirical evidence for fire-sales during the financial crisis. Our mechanism is similar to Diamond and Rajan (2005) in that (shadow) bank failures cause contagion by aggravating liquidity shortages in the rest of the financial sector.

Finally, like Diamond and Rajan (2011), we find that illiquidity leads to greater risk-taking by traditional banks. In Diamond and Rajan (2011), this is a consequence of risk-shifting whereas our finding arises due to interactions between deposit rates and market discipline that stem from threats of early withdrawal by depositors. Crucially, our mechanism can generate solvency risk ${ }^{5}$ where none previously existed, whereas the risk-shifting mechanism in Diamond and Rajan (2005) exacerbates pre-existing risks.

We proceed as follows: Section 2 presents motivating evidence from the 2008 financial crisis. Section 3 describes the core mechanisms of the model in a simple framework without liquidity risk. Section 4 presents the complete model with liquidity risk. Section 5 provides the numerical results. Section 6 conducts policy analysis. Section 7 concludes.

\section{Motivating evidence}

In this section, we present four key stylized facts about shadow banking and the 2008 financial crisis in the United States.

Fact 1. The shadow banking sector expanded rapidly until its collapse in 200\%. The traditional banking sector grew at a slower rate but did not suffer from a collapse.

\footnotetext{
${ }^{5}$ We distinguish between "solvency risk" which is the risk of fundamental insolvency after holding assets to maturity, and "liquidity risk" which refers to the prospect of bankruptcy due to withdrawals before assets reach maturity.
} 
Figure 1: Shadow and traditional bank assets

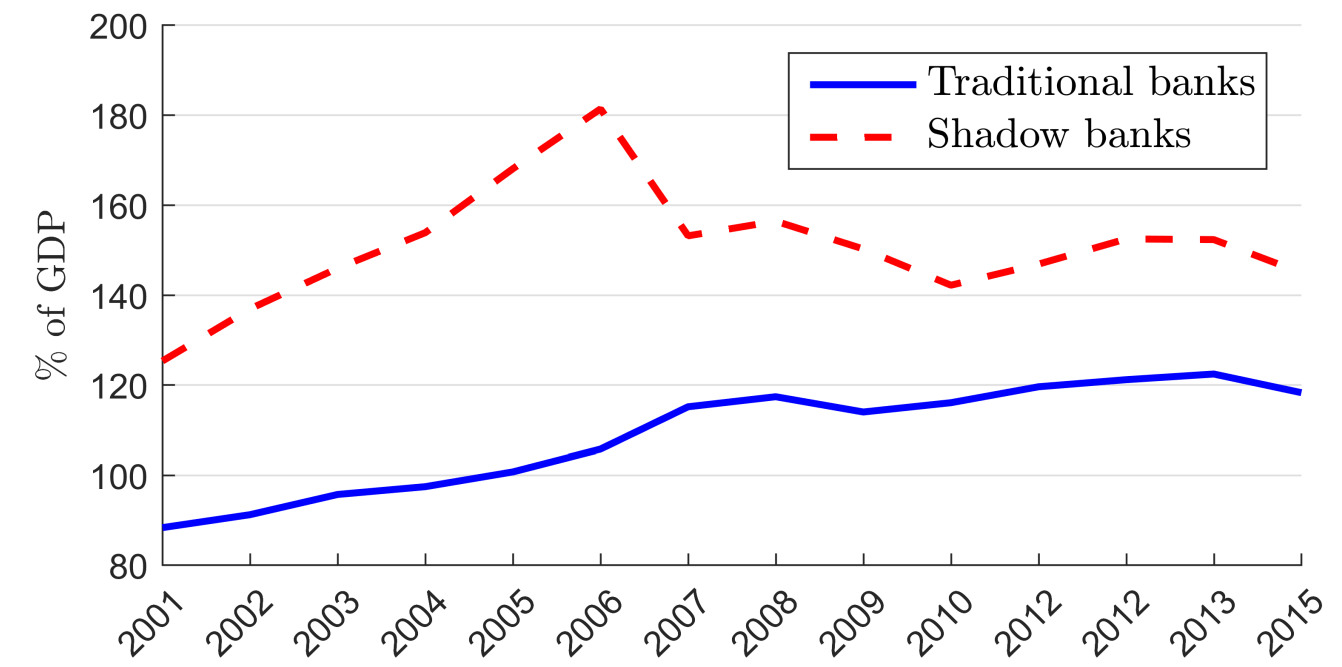

Note: Financial assets when available, otherwise total assets. Traditional banks refer to all deposit-taking corporations. Shadow banks refer to all financial corporations that are not classified as central banks, banks, insurance corporations, pension funds, public financial institutions, or financial auxiliaries.

Source: Financial Stability Board (2017) and the World Bank

Figure 1 shows that shadow bank assets expanded from 125\% of GDP in 2002 to over $180 \%$ at its peak in 2007. This rapid growth came to an end with a collapse during the financial crisis. In 2015, shadow bank assets amounted to 145\% of GDP. The traditional banking sector also expanded but at a relatively modest pace with its assets increasing from $88 \%$ of GDP in 2002 to $118 \%$ in 2015 . Although there was no contraction in traditional banking during the crisis, the shadow banking sector remained larger throughout the period 2002-2015.

In our model, the size of the shadow banking sector is endogenously determined through free entry and may rise for two reasons: an increase in the liquidity available in secondary markets and a rise in the cost of commitment. Recent financial innovations such as securitization may have increased both the commitment cost and the thickness of secondary markets. In Section 6 , we also analyze the role of policy interventions in the expansion of shadow banking. We show that expectations that policymakers will lean against a fire-sale increase the equilibrium size of the shadow banking sector in the same manner as the deepening of secondary markets. ${ }^{6}$

Fact 2. At the onset of the financial crisis, shadow banks experienced a sudden dry-up of funding and liquidated their assets.

At their peak of $\$ 1.2$ trillion in July 2007, asset-backed commercial papers (ABCP) were the largest money market instrument in the United States and constituted the main source

\footnotetext{
${ }^{6}$ This may be implemented directly through asset purchases or indirectly by bailing out financial institutions which would have contributed to the excess supply of assets.
} 
Figure 2: ABCP markets and shadow bank assets
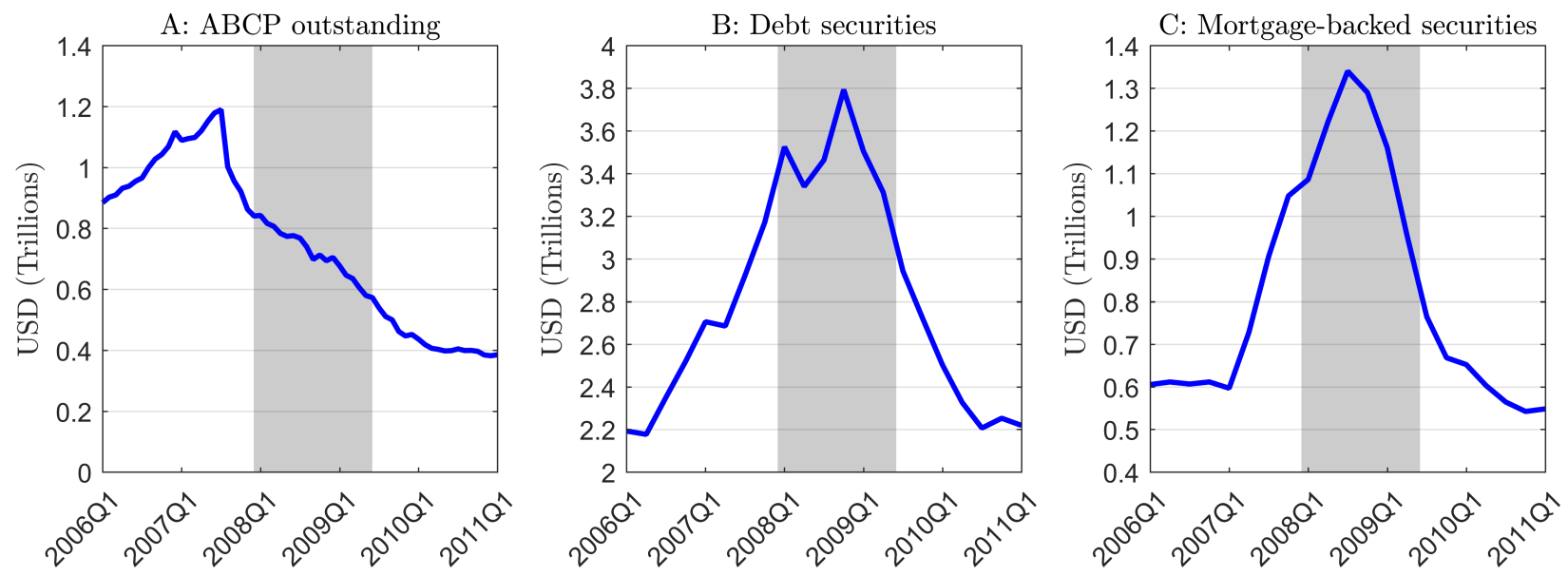

Note: Shaded areas indicate US recessions. Shadow banks refer to money market mutual funds, security brokers and dealers, and issuers of asset-backed securities. Mortgage-backed securities refer to agencyand GSE-backed securities.

Source: Financial Accounts of the United States

of funding for shadow banks. Following rising mortgage default rates and the suspension of withdrawals by a number of funds, the market for ABCP contracted by $\$ 350$ billion in the second half of 2007 and a further $\$ 400$ billion by the end of 2009 (see Panel A of Figure 2). Faced with this sudden contraction in funding, shadow banks liquidated their asset holdings. Panels B and C show that shadow banks sold $\$ 1.5$ trillions of debt securities between 2008Q3 and 2010Q1, approximately half of which were mortgage-backed securities. ${ }^{7}$

In our framework, shadow banks are vulnerable to early withdrawals which take place following an adverse change in macro-financial fundamentals: a bad news signal that leads to a downward revision in expected asset returns. These withdrawals constitute an optimal response by creditors to bad news rather than self-fulfilling bank-runs in the fashion of Diamond and Dybvig (1983).

During a withdrawal, shadow banks are forced to liquidate their assets in the secondary market. To the extent that this generates an adjustment in secondary market prices, there are consequences for traditional banks even in the absence of implicit guarantees or any other form of direct exposure between the traditional and shadow banking sectors.

Fact 3. Spreads between private debt securities and Treasury bonds increased sharply during the crisis. Securities with higher perceived risk experienced greater increases in spreads.

\footnotetext{
${ }^{7}$ It is notable that shadow banks' holdings of debt securities peaked in 2008Q3 nearly a year after the contraction in ABCP. One explanation is that shadow banks nearing bankruptcy prioritized the sale of liquid assets while increasing their exposure to higher yield mortgage-backed securities in a gamble for resurrection. See e.g. Ari (2017) for a model where banks facing adverse funding conditions and high aggregate risk find it optimal to behave in this manner.
} 
Figure 3: Spreads on corporate bonds

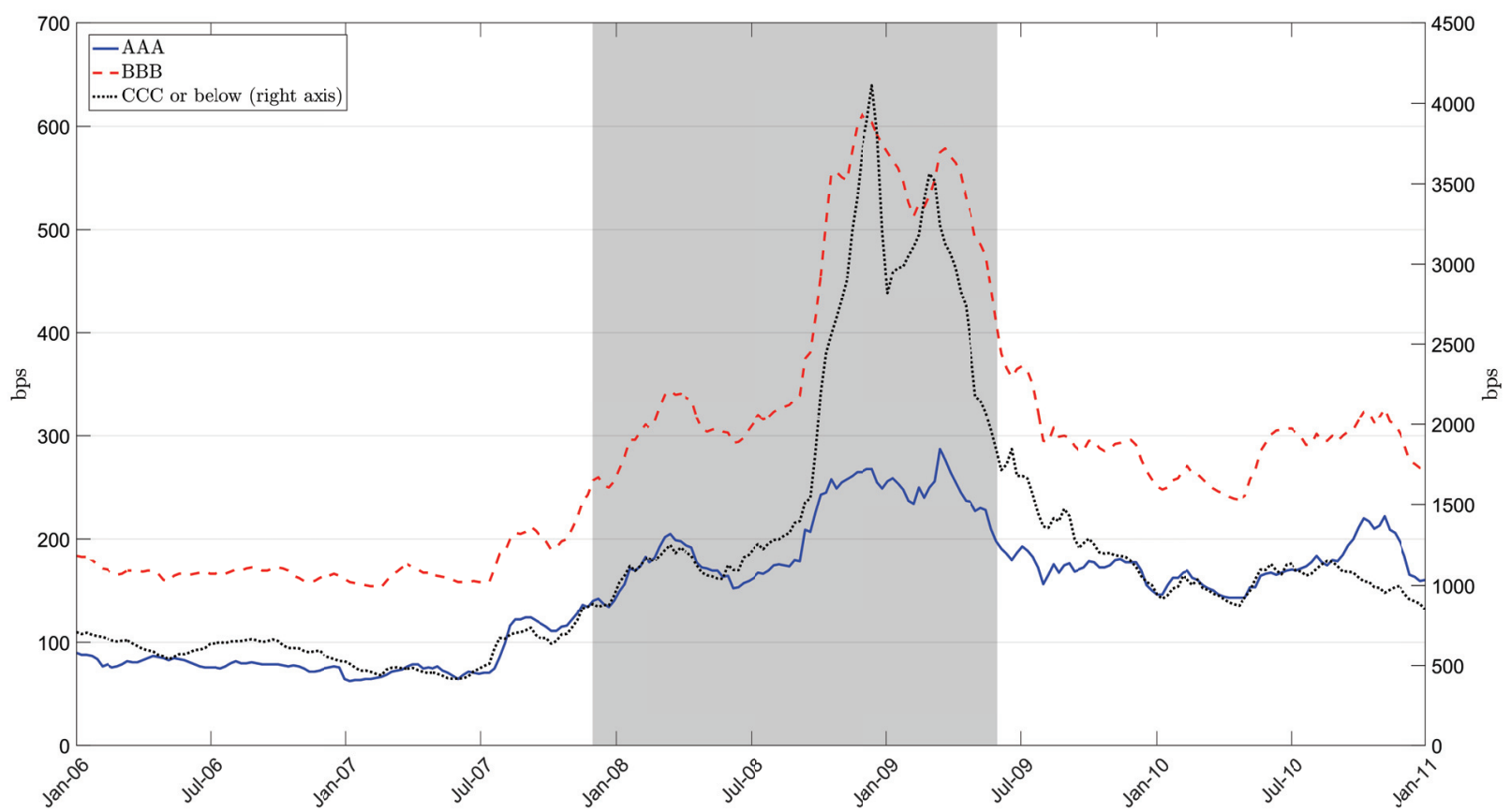

Note: Shaded areas indicate US recessions. AAA (BBB) refers to the spread between Moody's Seasoned Aaa (Baa) Corporate Bonds and 10-Year Treasury bonds (constant maturity). CCC or below refers to the option-adjusted spread between the Bank of America Merrill Lynch US Corporate C Index and a spot Treasury curve.

Source: Moody's Investor Services, Bank of America Merrill Lynch

Figure 3 shows the evolution of yield spreads between corporate bonds (grouped according to their credit rating) and Treasury bonds of comparable maturity. It is notable that spreads peaked in the last quarter of 2008, coinciding with the liquidation of shadow bank assets. Although there was a sharp rise in spreads for every rating category, the increase was greater for lower-rated corporate bonds.

Our model generates changes in secondary market prices that are consistent with these movements in spreads. When there is cash-in-the-market pricing, the liquidation of shadow bank portfolios causes a fire-sale and (illiquid) assets trade at a significant discount. Portfolio re-allocation by traditional banks from risky to safe and liquid assets also contributes to the fire-sale. We provide evidence for and further discuss portfolio re-allocation under Fact 4.

Fact 4. Traditional banks re-allocated their portfolios toward safe and liquid assets and were able to increase their liabilities. At the same time, they faced a rise in their funding costs.

Panel A of Figure 4 shows that traditional banks increased their liabilities during the crisis. Although the increase in liabilities was driven by Federal Reserve funding and a rise in deposits protected by deposit insurance guarantees, there was also no decline in large time deposits. Since large time deposits are neither checkable, nor insured, the implication is that 
Figure 4: Traditional banks during the crisis
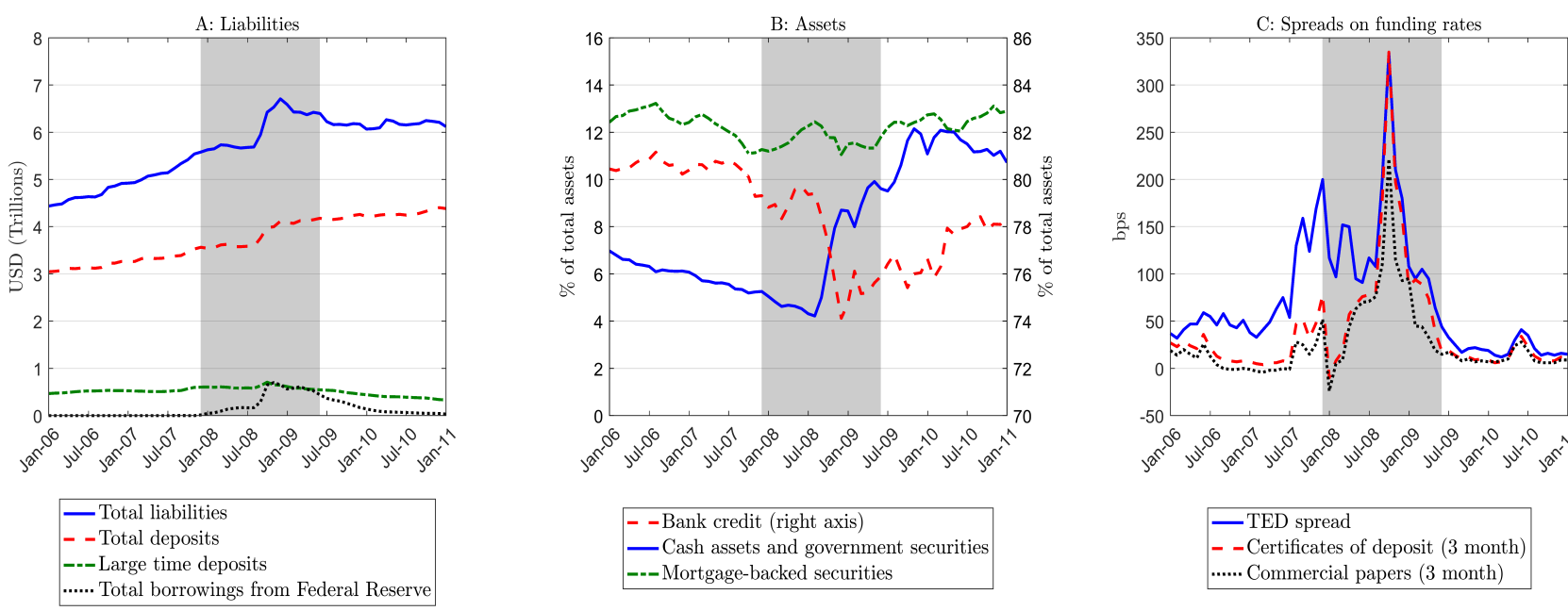

Note: Shaded areas indicate US recessions. Traditional banks refers to "large domestically chartered commercial banks" which are defined as the top 25 domestically chartered commercial banks, ranked by domestic assets. Cash assets and govenment securities include vaullt cash, cash items in process of collection, balances due from depository institutions and Federal Reserve Banks, and liabilities of the U.S. government, U.S. government agencies and U.S. government-sponsored enterprises. The TED spread is calculated as the spread between LIBOR based on US dollars and Treasury Bills. Certificate of deposit and commercial paper spreads are between the secondary market rates of these securities and the Effective Federal Funds Rate. All spreads refer to 3 month maturities.

Source: Board of Governors of the Federal Reserve System, the Federal Reserve Bank of St. Louis

traditional banks were perceived to be safe enough to preclude withdrawals even in the absence of government guarantees.

Changes in traditional bank portfolios shown in Panel B lend further support to this interpretation. During the crisis, traditional banks re-allocated their portfolios from bank credit (which is risky and illiquid) to cash assets and government securities (which are liquid and safe). Mortgage-backed securities that were at the epicenter of the financial crisis accounted for only $12 \%$ of total assets and this did not change significantly over the crisis.

It is important to note, however, that while traditional banks did not experience a dry-up in funding, there was a significant increase in their funding costs. Panel $\mathrm{C}$ shows that the TED spread (for interbank loans) increased to 200 basis points in December 2007 and 335 basis points in October 2008. The spreads on certificates of deposits and commercial papers also increased significantly.

In the following sections, we show that the interaction between market discipline and liquidity risk may account for these observations. In our framework, market discipline stems from the threat of early withdrawal by depositors. To avoid an early withdrawal, traditional banks commit to a minimum recovery rate on deposits (in other words a maximum loss given default) which we refer to as a "no-withdrawal constraint" and respond to bad news by re-allocating their portfolios towards safe assets. 
The fire-sale discussed under Fact 3 interacts with this mechanism through two distinct transmission channels. First, since risky assets are discounted to a greater extent than safe assets, it reduces traditional banks' capacity for portfolio re-allocation. To satisfy the nowithdrawal constraint, traditional banks are then forced to reduce their risky asset holdings exante. This creates an excess return that increases the expected payoff associated with traditional banking. As the extent of the fire-sale is proportionate to the size of the shadow banking sector, equilibrium is achieved through this mechanism. In the next section, we analyze this mechanism and the properties of the equilibrium in a simple model without liquidity risk.

Second, the fire-sale leaves traditional banks illiquid. This drives a wedge between solvency and liquidity, leaving traditional banks vulnerable to self-fulfilling bank-runs as per Diamond and Dybvig (1983). In Sections 4 and 5, we extend the simple model to allow for liquidity risk (i.e. the possibility of bank runs) and show that this undermines market discipline on traditional banks: Depositors demand higher interest rates to compensate for liquidity risk, generating a rise in deposit rates similar to Panel C. Higher deposit rates in turn weaken the threat of early withdrawal, bringing about a relaxation in the no-withdrawal constraint and greater risk-taking by traditional banks. In equilibrium, the shadow banking sector reaches a size that causes financial instability through this mechanism.

\section{A simple model}

We consider a financial economy populated by four agents: households, banks, entrepreneurs, and outside investors. Events unfold over three time periods (see Figure 5 for a graphical timeline). In the first period, banks collect deposits from households and invest in (safe and liquid) cash and (risky and illiquid) assets originated by entrepreneurs. ${ }^{8}$

The second period begins with a public news signal that leads to a revision of expected asset returns. With probability $q$, the signal harbors "bad news" leading to a decline in expected asset returns. After observing the signal, households decide whether to withdraw their deposits early and banks trade assets with outside investors in a secondary market.

In the third period, assets yield a high or low payoff contingent on economic fundamentals. Following bad news in the second period, fundamentals may turn out to be weak with (conditional) probability $p$, leading to a low payoff from assets. Depending on their investment strategy, banks may then be left with insufficient funds to pay the promised return to their depositors. In this case, they become insolvent under limited liability and a haircut proportionate

\footnotetext{
${ }^{8}$ In Section 4, we also introduce a safe but illiquid asset.
} 
Figure 5: Timeline

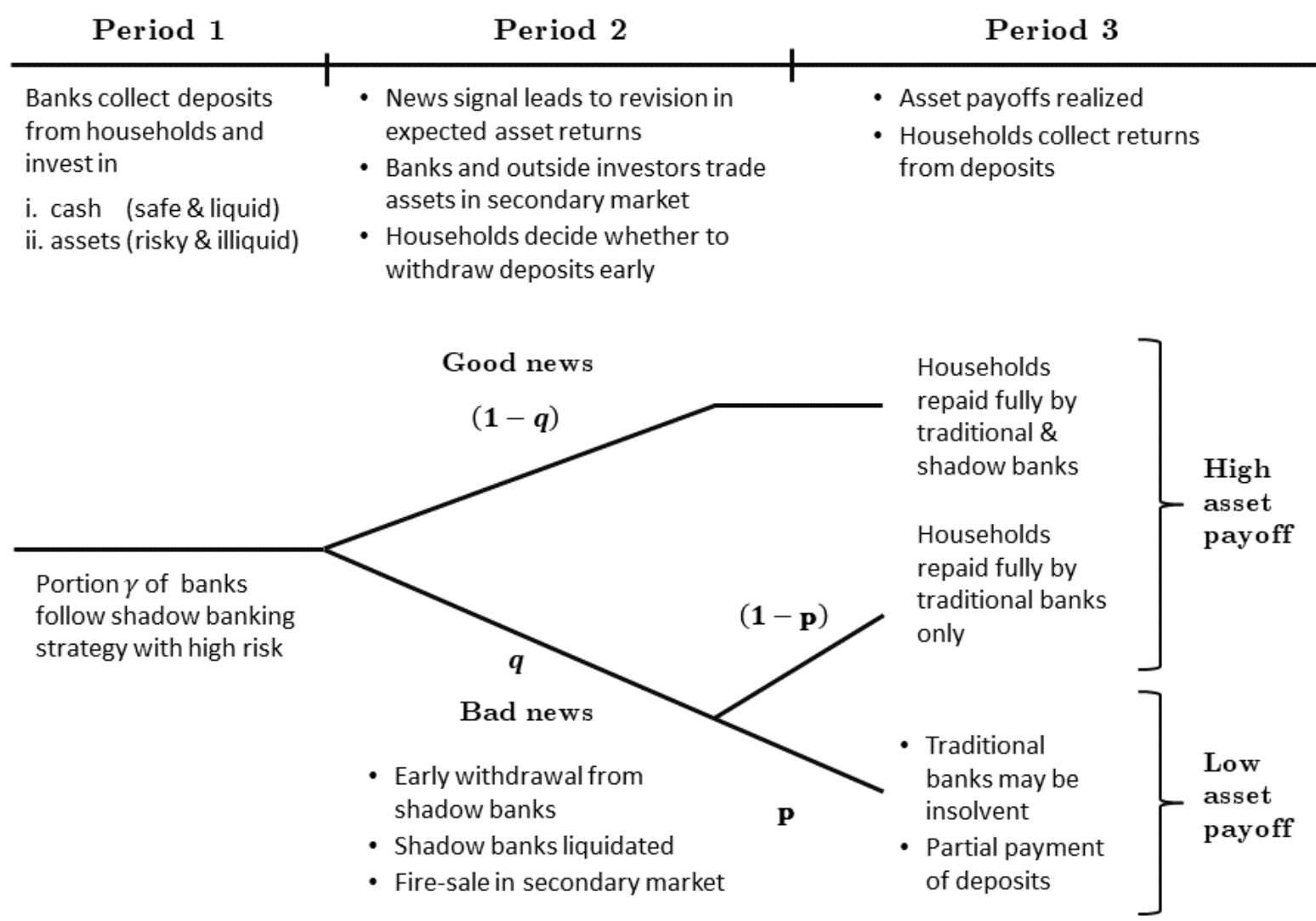

to their funding shortfall is imposed on deposits. ${ }^{9}$

The key friction in the model is costly commitment. Specifically, we assume that banks cannot credibly commit to a safe investment strategy unless they pay a commitment cost $\tau>0 .{ }^{10}$ Due to this friction, ex-ante identical banks optimally cluster into two distinct groups according to their investment strategies. An endogenous share $\gamma \in[0,1]$ of banks do not pay the commitment cost and follow a shadow banking strategy that entails high risk-taking. Following bad news, households optimally withdraw their deposits from shadow banks due to concerns about their solvency prospects. Shadow bank assets are then liquidated in the secondary market at an endogenous fire-sale discount and depositors receive the liquidation value. The remaining banks pay the cost $\tau$ to credibly commit to a portfolio that is safe enough to prevent an early

\footnotetext{
${ }^{9}$ Fundamentals turn out to be strong with certainty after good news (which takes place with probability $(1-q))$ and with (conditional) probability $(1-p)$ after bad news. In this case, assets yield a high payoff and banks are solvent.

${ }^{10}$ We do not explicitly model the underlying principal-agent problem between banks and their depositors but provide two motivating examples. First, bank balance sheets may not be fully transparent. The commitment cost would then reflect any costly action taken by banks to increase transparency such as abiding by reporting requirements or foregoing opaque intermediation processes such as securitization. Second, limited enforcement of contracts may allow banks to revise their investment strategies after collecting deposits. The commitment cost could then be in the form of issuing costly equity with voting rights.
} 
withdrawal. We refer to this as a 'traditional banking' strategy.

It is important to note that early withdrawals are distinct from self-fulfilling (DiamondDybvig) bank-runs, as they are an optimal response to a change in banks' solvency prospects rather than a consequence of strategic complementarities across households. In other words, an early withdrawal takes place when households find it optimal to withdraw their deposits regardless of the extent of withdrawals by other households.

Before explaining these activities in detail, we briefly describe some notational conventions. Table 1 provides a list of variables and parameters. We denote variables that pertain to a shadow (traditional) banking strategy with a superscript ' $S B$ ' (' $T B$ '). Deposits, cash and (risky) assets are respectively labelled as $(D, M, I)$. To distinguish between deposits per bank and per household, we denote the latter as $d$ in lower case. The effective return from deposits is contingent on solvency and the time of withdrawal. Upon maturity in the third period, deposits pay an interest rate $R$ when the bank is solvent and a recovery rate $V$ otherwise. When they are withdrawn early, deposits pay a liquidation value $\theta$. Asset prices in the first and second period are labelled as $\left(P_{1}, P_{2}\right)$. In period 3 , assets yield a payoff $\sigma_{h}$ when fundamentals are strong and $\sigma_{l}$ otherwise. We simplify notation by normalizing the risk-free rate to $R^{*}=1$ and the unconditional expectation of asset payoffs to unity such that ${ }^{11}$

$$
(1-q p) \sigma_{h}+q p \sigma_{l}=1
$$

\subsection{Agents and their optimal strategies}

\subsubsection{Entrepreneurs}

In the first period, each bank has access to a separate but ex-ante identical island of entrepreneurs which use capital $K$ to produce assets $I_{1}$ with a Cobb-Douglas production technology

$$
I_{1}=A K^{\alpha}
$$

where $A>0$ is a productivity parameter and $\alpha \in(0,1)$ is the standard Cobb-Douglas elasticity. The representative entrepreneur's problem can be written as

$$
\max _{I_{1}, K} P_{1} I_{1}-K
$$

\footnotetext{
${ }^{11}$ Note that assets may still have a return above unity since $\left(P_{1}, P_{2}\right)$ are endogenous.
} 


\section{Variables}

\begin{tabular}{|c|l|}
\hline Label & \multicolumn{1}{|c|}{ Description } \\
\hline \hline$D$ & Deposits (per bank) \\
$d$ & Deposits (per household) \\
$I$ & Assets \\
$M$ & Cash \\
$R$ & Interest rate on deposits \\
$K$ & Capital \\
$P_{1}, P_{2}$ & Asset prices \\
$\widetilde{I}$ & Excess supply in secondary market \\
$\widetilde{K}$ & Outside project \\
$\phi$ & Fire-sale discount \\
$\theta$ & Liquidation value \\
$V$ & Recovery rate \\
$\Pi$ & Bank profits \\
$\gamma$ & Share of shadow banks \\
$C$ & Consumption \\
\hline
\end{tabular}

Parameters

\begin{tabular}{|c|l|}
\hline Label & \multicolumn{1}{|c|}{ Description } \\
\hline \hline$q$ & Prob. of bad news \\
$p$ & Prob. of weak fundamentals \\
$\sigma_{h}, \sigma_{l}$ & Asset payoffs \\
$A$ & Productivity \\
$\alpha$ & Cobb-Douglas elasticity \\
$R^{*}$ & Risk-free rate \\
$E$ & Household endowment \\
$\widetilde{E}$ & Outside investor endowment \\
$\tau$ & Commitment cost \\
\hline
\end{tabular}

subject to the production technology (2) where $P_{1}$ is the asset price. ${ }^{12}$ This yields a first order condition that can be interpreted as an upward-sloping asset supply schedule

$$
P_{1}=\frac{1}{\alpha A^{\frac{1}{\alpha}}} I^{\frac{1-\alpha}{\alpha}}
$$

Due to relationship lending frictions, banks may only purchase assets from entrepreneurs in their own island. ${ }^{13,14}$ This also constitutes a barrier to entry that gives banks market power over entrepreneurs, allowing them to extract a mark-up

$$
\frac{\partial P_{1}}{\partial I_{1}} \frac{I_{1}}{P_{1}}=\mu>0
$$

In the interest of tractability, we do not explicitly model the bargaining process between banks

\footnotetext{
${ }^{12}$ We normalize the rental rate of capital to unity.

${ }^{13}$ Implicitly, we assume that entrepreneurs may costlessly produce a pseudo-asset that pays zero return and banks may only monitor entrepreneurs in their own island. The same friction also bars households from investing directly in assets.

${ }^{14} \mathrm{We}$ also assume that banks may only trade assets in the second period. Therefore, the asset price $P_{1}$ is specific to each bank and is best interpreted as the cost of origination rather than the price of a tradable asset.
} 
and entrepreneurs but restrict the mark-up to

$$
\mu \leq \bar{\mu} \equiv \frac{(1-q)\left(\sigma_{h}-1\right)}{1-(1-q) \sigma_{h}}
$$

This restriction only serves to simplify the bank's problem in Section 3.1.4 and we show in Appendix D.2 that it can be relaxed without altering the properties of the equilibrium solution.

\subsubsection{Secondary market and outside investors}

In the second period, banks and outside investors trade assets in a secondary market. First, we consider the case after good news. Since assets yield a high payoff $\sigma_{h}$ with certainty after good news, there are no early withdrawals. Secondary markets then clear without a fire-sale at a price $\sigma_{h}$. Whilst trade may take place, the pricing of assets at their expected payoff ensures that it is completely inconsequential to the equilibrium allocation. Therefore, we abuse notation slightly by using the subscript 2 to denote variables after bad news throughout the paper.

Following bad news, the liquidation of shadow banks and portfolio re-allocation by traditional banks leads to an excess supply of assets

$$
\widetilde{I}=\gamma I_{1}^{S B}+(1-\gamma)\left(I_{1}^{T B}-I_{2}^{T B}\right)>0
$$

where $\gamma$ is the share of shadow banks within the banking sector, $I_{1}^{S B}$ is shadow bank assets, and the second term represents the net sale of assets by traditional banks. Outside investors with a lower valuation for assets then become the marginal buyers and the secondary market price is given by

$$
P_{2}=\phi\left[(1-p) \sigma_{h}+p \sigma_{l}\right]
$$

where the fire-sale discount $\phi \in[0,1]$ adjusts to clear markets and the term in brackets is the expected payoff conditional on bad news.

Our set up for outside investors is based on Stein (2012). Outside investors begin the second period with an endowment $\widetilde{E}$ and allocate their funds between asset purchases in the secondary market and an outside project $\widetilde{K}$ that yields a safe payoff $g(\widetilde{K})$ where $g^{\prime}()>$.0 , $g^{\prime \prime}()<$.0 . Their first order condition equates the expected return between the two investment opportunities and yields an implicit expression for the market-clearing fire-sale discount.

$$
\phi=\frac{1}{g^{\prime}\left(\widetilde{E}-\phi\left[(1-p) \sigma_{h}+p \sigma_{l}\right] \widetilde{I}\right)}
$$

Without loss of generality, we can write this as $\phi=f(\widetilde{I})$ where $f($.$) is a continuous and$ decreasing function. 
We restrict the fire-sale discount to values within the range $\phi \in(\underline{\phi}, \bar{\phi}]$ by imposing the following restrictions on $f($.$) (and hence on \widetilde{E}$ and $g($.$) )$

$$
\underline{\phi}<f\left(\left(A \alpha^{\alpha}\right)^{\frac{1}{1-\alpha}}\left((1-q) \frac{\sigma_{h}}{1+\mu}+q \sigma_{l}\right)^{\frac{\alpha}{1-\alpha}}\right)<\bar{\phi}
$$

where

$$
\begin{aligned}
\underline{\phi} & \equiv \frac{\sigma_{l}}{(1-p) \sigma_{h}+p \sigma_{l}} \geq 0 \\
\bar{\phi} & \equiv \min \left[1, \frac{(1-q) \frac{\sigma_{h}}{1+\mu}+q \sigma_{l}}{(1-p) \sigma_{h}+p \sigma_{l}}\right]>\underline{\phi}
\end{aligned}
$$

The upper bound of this restriction ensures that the fire-sale deepens as the shadow banking sector grows, and is necessary for bringing about an interior equilibrium where shadow and traditional banks coexist. ${ }^{15}$ The lower bound, on the other hand, only serves to simplify our exposition by eliminating the possibility of an (interior) equilibrium case with slightly different properties to the one we describe in Section 3.2. We discuss the consequences of relaxing the lower bound restriction in Appendix E.

\subsubsection{Households}

There is a unit continuum of risk neutral households which derive utility only from final period consumption, making their utility maximization problem equivalent to maximizing expected consumption $^{16}$

$$
E[C]=(1-q) C_{g h}+q(1-p) C_{b h}+q p C_{b l}
$$

where $\left(C_{g h}, C_{b h}, C_{b l}\right)$ are respectively consumption under good news and bad news with high and low payoff from assets. In the first period, households allocate their endowment $E$ between deposits in traditional and shadow banks $\left(d^{T B}, d^{S B}\right)$ and cash $M_{1}$ which transfers funds to the next period at zero net return. The first period budget constraint is

$$
d^{S B}+d^{T B}+M_{1}=E
$$

When the second period begins with good news, there are no withdrawals and households simply retain their cash holdings $M_{1}$. In the third period, consumption is then given by

$$
C_{g h}=M_{1}+d^{T B} R^{T B}+d^{S B} R^{S B}
$$

\footnotetext{
${ }^{15}$ See Section 3.2 for a formal definition.

${ }^{16}$ These assumptions only serve to simplify the exposition. Our findings remain the same under risk aversion and period-by-period discounting.
} 
where $\left(R^{T B}, R^{S B}\right)$ represent the deposit interest rates at traditional and shadow banks.

Following bad news, on the other hand, households observe the decline in expected asset returns and decide whether to withdraw their deposits early. Before we consider this decision, we solve the household's optimization problem in the first period taking it as given that only shadow banks face an early withdrawal. The second period budget constraint under bad news can then be written as

$$
M_{2}=M_{1}+\theta^{S B} d^{S B}
$$

where $\theta^{S B}$ is the liquidation value of shadow bank portfolios. In the third period, traditional banks may be rendered insolvent by a low payoff from assets. Therefore, consumption is contingent on asset payoffs

$$
\begin{aligned}
C_{b h} & =M_{2}+d^{T B} R^{T B} \\
C_{b l} & =M_{2}+V d^{T B} R^{T B}
\end{aligned}
$$

with $V$ representing the recovery rate of traditional bank deposits. ${ }^{17}$

The representative household chooses $\left\{d^{T B}, d^{S B}, M_{1}, M_{2}\right\}$ to maximize its expected consumption (7) subject to (8)-(12). The first order conditions yield the following expressions for interest rates

$$
\begin{aligned}
R^{T B} & =1+\frac{q p(1-V)}{1-q p(1-V)} \\
R^{S B} & =1+\frac{q}{1-q}\left(1-\theta^{S B}\right)
\end{aligned}
$$

Observe that the interest rate on traditional bank deposits decreases with a rise in the recovery rate $V$, while that of shadow banks decreases with a higher liquidation value $\theta^{S B}$. Traditional banks may borrow at the risk-free rate $R^{T B}=1$ when they guarantee a complete repayment of deposits $V=1$ while shadow banks must be completely liquid with $\theta^{S B}=1$.

\section{Early withdrawal decision and market discipline}

Following bad news, it is optimal for households to withdraw their deposits when doing so increases their expected consumption $(1-p) c_{b h}+p c_{b l}$ conditional on bad news. Proposition 1 describes the outcome of the early withdrawal decision.

Proposition 1 For all $\phi>\underline{\phi}$, it is optimal for households to withdraw their deposits from shadow banks after bad news. Traditional banks may avoid an early withdrawal by committing

\footnotetext{
${ }^{17}$ The liquidation value $\theta^{S B}$ and recovery rate $V$ are endogenous and depend on the investment strategy of traditional and shadow banks. We elaborate further on this in Section 3.1.4.
} 
to a minimum recovery rate

$$
V \geq \bar{V} \equiv \frac{1}{p}\left(\frac{1}{R^{T B}}-(1-p)\right)
$$

In equilibrium, the recovery rate and interest rates on traditional bank deposits are given by

$$
\bar{V}=R^{T B}=1
$$

Proof. Provided in Appendix A

Note that (15) establishes a no-withdrawal constraint for traditional banks. This constraint is the key difference between shadow and traditional banking strategies, and generates similar behaviour to the observations discussed under Fact 4. To satisfy this constraint, traditional banks react to bad news by re-allocating their portfolio from risky to safe assets.

The proposition also shows that the no-withdrawal constraint imposes market discipline on traditional banks, eliminating insolvency risk and reducing their funding costs to the risk-free rate. This is the outcome of a virtuous cycle between deposit rates $R^{T B}$ and the minimum recovery rate $\bar{V}$. As traditional banks guarantee a minimum recovery rate, households demand less compensation for insolvency risk and deposit rates decrease as per (13). Lower deposit rates in turn strengthen the threat of early withdrawal as households stand to lose less in terms of interest foregone. Therefore, the minimum recovery rate $\bar{V}$ increases until all solvency risk is eliminated in equilibrium.

It is important to note that this result is contingent on the lack of liquidity risk. In Section 4, we show that even a small risk of a (Diamond-Dybvig) bank run on traditional banks reverses this virtuous cycle, leading to a rise in insolvency risk and funding costs.

\subsubsection{Banks}

There is a unit continuum of ex-ante identical, risk neutral banks. In the first period, banks

collect deposits $D$ from households and purchase assets $I_{1}$ from entrepreneurs at price $P_{1}$ as well as holding cash $M_{1}$. Their first period budget constraint can then be written as

$$
P_{1} I_{1}+M_{1}=D
$$

In the second period, banks trade assets in the secondary market. As discussed in Section 3.1.2, following good news, assets are priced at their expected payoff in the secondary market and trade is inconsequential. Bank profits (in the third period) are given by

$$
\Pi_{g h}=\sigma_{h} I_{1}+M_{1}-D R
$$


Following bad news, banks that are subject to an early withdrawal have a liquidation value

$$
\theta=\min \left\{1, \frac{P_{2} I_{2}+M_{2}}{D}\right\}
$$

and those that are not face the second period budget constraint

$$
P_{2} I_{2}+M_{2}=P_{2} I_{1}+M_{1}
$$

Observe that a fire-sale reduces the liquidation value as well as the maximum cash $M_{2}$ banks may attain through portfolio re-allocation. When assets yield a high payoff $\sigma_{h}$ in the third period, banks make a profit

$$
\Pi_{b h}=\sigma_{h} I_{2}+M_{2}-D R
$$

while limited liability binds under a low asset payoff $\sigma_{l}{ }^{18}$ Under limited liability, banks make zero profits and deposits pay a recovery rate

$$
V=\min \left\{1, \frac{\sigma_{l} I_{2}+M_{2}}{D R}\right\}
$$

which is proportional to the shortfall of funds.

The commitment cost $\tau>0$ creates a discontinuity in the optimization problem of banks such that it can be evaluated as a choice between two distinct investment strategies. Under a shadow banking strategy (labelled as ' $S B$ '), banks do not pay the commitment cost and anticipate an early withdrawal after bad news. Under a traditional banking strategy (labelled as ' $T B$ '), banks pay the cost $\tau$ and commit to satisfying the no-withdrawal constraint (15). We find it convenient to to write the no-withdrawal constraint in terms of the choice variables by combining (15) and (20). ${ }^{19}$

$$
\sigma_{l} I_{2}^{T B}+M_{2}^{T B} \geq \bar{V} D^{T B} R^{T B}
$$

In the first period, banks adopt the strategy that leads to the highest expected payoff such that shadow banking is preferred when

$$
E\left[\Pi^{S B}\right] \geq E\left[\Pi^{T B}\right]-\tau
$$

where $E\left[\Pi^{S B}\right]$ and $E\left[\Pi^{T B}\right]$ are the expected payoffs associated with shadow and traditional banking. Below, we solve the optimization problem under each strategy and attain an expression

\footnotetext{
${ }^{18}$ See Appendix B for the relevant proof.

${ }^{19}$ To simplify the exposition, we treat the commitment cost $\tau$ as a utility cost, thereby omitting it from the no-withdrawal and budget constraints. Since $\tau$ is small relative to total bank assets, its inclusion would have a negligible impact on the equilibrium outcome.
} 
for expected payoffs by combining banks' first order conditions with those of households from Section 3.1.3. In doing so, we take the secondary market price $P_{2}$ as given.

\section{Shadow banking}

Shadow banks choose $\left\{I_{1}^{S B}, M_{1}^{S B}, D^{S B}\right\}$ to maximize their expected profits

$$
E\left[\Pi^{S B}\right]=(1-q)\left(\sigma_{h} I_{1}^{S B}+M_{1}^{S B}-D^{S B} R^{S B}\right)
$$

subject to the budget constraint (17). Since limited liability binds after an early withdrawal, shadow banks only internalize the payoff after good news. Lemma 1 provides the solution the shadow bank's problem. It shows that, even without a fire-sale, shadow bank deposits are not paid in full during an early withdrawal $\left(\theta^{S B}<1\right)$ and funding costs of shadow banks are above the risk free rate $\left(R^{S B}>1\right)$ as a consequence.

Lemma 1 Combining the solution to the shadow bank's problem given by (35) and (36) with the household first order condition (14) yields the following expressions for $\left(\theta^{S B}, R^{S B}, E\left[\Pi^{S B}\right], I_{1}^{S B}\right)$

$$
\begin{aligned}
\theta^{S B} & =\frac{(1+\mu) P_{2}}{(1-q) \sigma_{h}+q(1+\mu) P_{2}}<1 \forall \phi \in[0,1] \\
R^{S B} & =\frac{\sigma_{h}}{(1-q) \sigma_{h}+q(1+\mu) P_{2}}>1 \forall \phi \in[0,1] \\
E\left[\Pi^{S B}\right] & =(1-q) \frac{\mu}{1+\mu} \sigma_{h} I_{1}^{S B} \\
I_{1}^{S B} & =\left(A \alpha^{\alpha}\right)^{\frac{1}{1-\alpha}}\left((1-q) \frac{\sigma_{h}}{1+\mu}+q P_{2}\right)^{\frac{\alpha}{1-\alpha}}
\end{aligned}
$$

Proof. Provided in Appendix C

Figure 6 provides a graphical representation of the shadow banking strategy. The red line depicts banks' demand for deposits, which is inversely related to the asset price $P_{1}$. As deposits are used to purchase risky assets $I_{1}$, its downward slope reflects the positive relationship between $I_{1}$ and $P_{1}$ given by the asset supply schedule (3). The blue line depicts the supply of deposits by households. It is horizontal at the risk-free rate $R=1$ when there is no early withdrawal or $\theta=1$, but becomes upward sloping when a rise in $P_{1}$ reduces the liquidation value $\theta$ and drives households to require a higher interest rate in compensation as per (14). Under a shadow banking strategy, banks optimally invest up to the intersection of these two curves where the funding costs exceed the risk-free rate. 
Figure 6: Shadow banking strategy

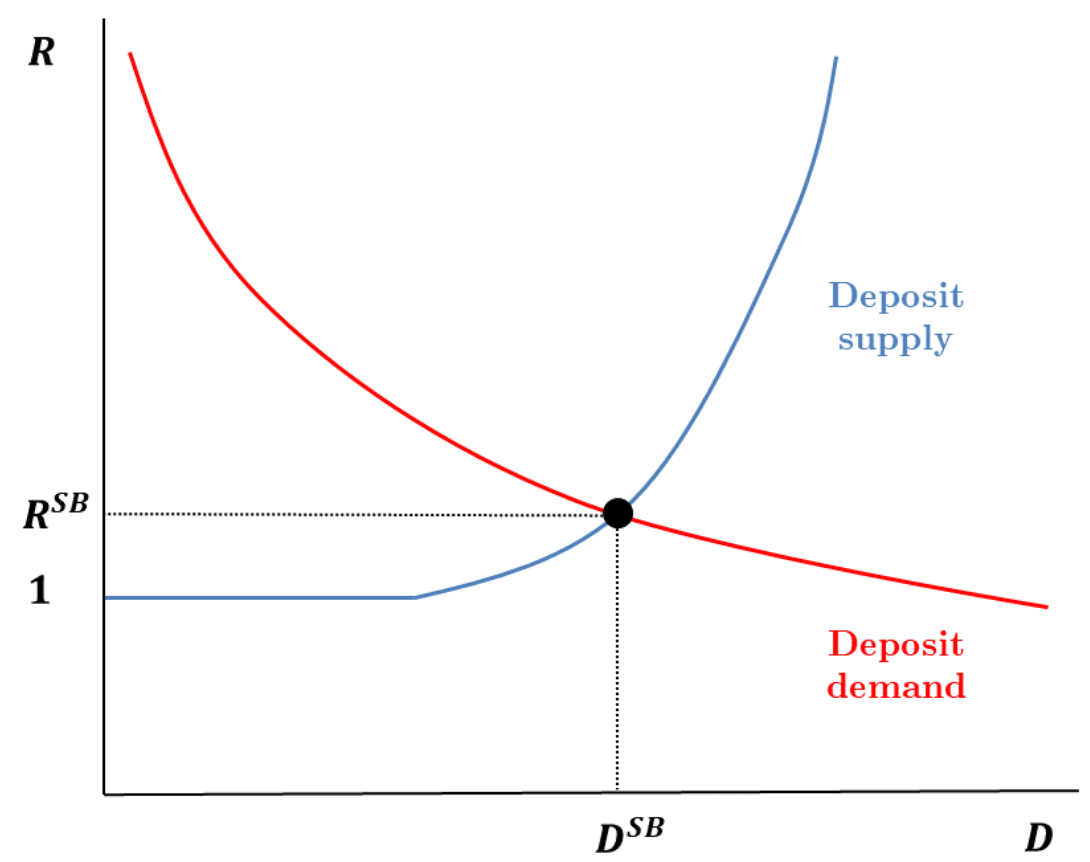

Note: The deposit demand curve is attained by combining (3) and (17). Deposit supply stems from (14) and (35).

\section{Traditional banking}

Traditional banks choose $\left\{I_{1}^{T B}, I_{2}^{T B}, M_{1}^{T B}, M_{2}^{T B}, D^{S B}\right\}$ to maximize their expected profits

$$
E\left[\Pi^{T B}\right]=(1-q)\left(\sigma_{h} I_{1}^{T B}+M_{1}^{S B}\right)+q(1-p)\left(\sigma_{h} I_{2}^{T B}+M_{2}^{T B}\right)-(1-q p) D^{T B} R^{T B}
$$

subject to the budget constraints (17), (19) and the no-withdrawal constraint (21). ${ }^{20}$

Lemma 2 provides the solution to the traditional bank's problem. ${ }^{21}$ It shows that, following bad news, traditional banks liquidate their risky asset holdings in the secondary market and re-allocate their portfolio toward cash to satisfy the no-withdrawal constraint. ${ }^{22}$ Since the terms of trade between risky assets and cash depend on the secondary market price $P_{2}$, the no-withdrawal constraint also reduces banks' risky asset purchases $I_{1}$ in period 1 in line with $P_{2}$. Since the funding costs of traditional banks remain at the risk-free rate $\left(R^{T B}=1\right)$, this creates an excess return that contributes to traditional bank profits (see Figure 7 for a graphical

\footnotetext{
${ }^{20}$ Due to limited liability, traditional banks do not internalize the state with low payoff from assets.

${ }^{21}$ The indeterminacy of $M_{1}^{T B}$ is due to two reasons. First, it does not contribute towards the no-withdrawal constraint, since each extra unit of cash corresponds to an extra unit of deposit. Second, the no-withdrawal constraint also prevents banks from converting cash to risky assets after bad news such that bank profits are not affected by $M_{1}^{T B}$.

${ }^{22}$ The complete liquidation of risky assets $\left(I_{2}^{T B}=0\right)$ and the equivalence between first and second period asset prices $\left(P_{1}^{T B}=P_{2}\right)$ are due to the simplifying restrictions we have made in the interest of tractability. In Section 5, we show that the mechanism remains intact in a richer model which generates positive risky asset holdings after the sell-off and $P_{1}^{T B}>P_{2}$.
} 
Figure 7: Traditional banking strategy

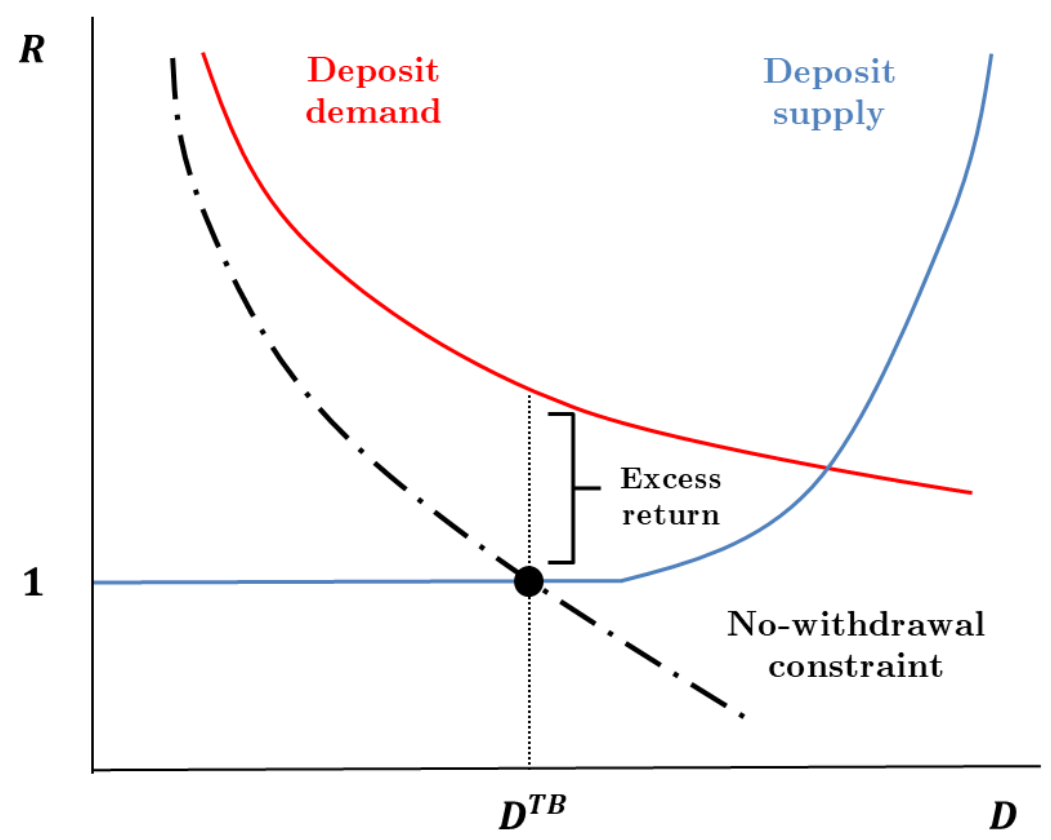

Note: The deposit demand curve is attained by combining (3) and (17). Deposit supply stems from (14) and (35). The no-withdrawal constraint is given by (21), (24), and (25).

representation).

Lemma 2 Under the restrictions $\mu \leq \bar{\mu}, \phi>\underline{\phi}$, the solution to the traditional bank's problem is

$$
\begin{aligned}
I_{1}^{T B} & =\left(A \alpha^{\alpha}\right)^{\frac{1}{1-\alpha}} P_{2}^{\frac{\alpha}{1-\alpha}} \\
I_{2}^{T B} & =0 \\
M_{2}^{T B} & =P_{2} I_{1}^{T B}+M_{1}^{T B} \\
E\left[\Pi^{T B}\right] & =(1-q)\left(\sigma_{h}-P_{2}\right) I_{1}^{T B}
\end{aligned}
$$

where $M_{1}^{T B} \geq 0$ is indeterminate, $\left(R^{T B}, \bar{V}\right)$ are given by (16), and

$$
\frac{\partial E\left[\Pi^{T B}\right]}{\partial P_{2}}<0 \forall P_{2}>\alpha \sigma_{h}
$$

Proof. Provided in Appendix D. 


\subsection{Equilibrium}

We solve for a rational expectations equilibrium such that all optimality conditions and constraints of banks, households, entrepreneurs and outside investors are satisfied, expectations are confirmed, and deposit and secondary markets clear such that

$$
\begin{gathered}
\gamma D^{S B}=d^{S B} \\
(1-\gamma) D^{T B}=d^{T B} \\
\phi=f\left(\gamma I_{1}^{S B}+(1-\gamma)\left(I_{1}^{T B}-I_{2}^{T B}\right)\right)
\end{gathered}
$$

where $\gamma \in[0,1]$ is the share of banks that adopt a shadow banking strategy.

Furthermore, an equilibrium is characterized as 'interior' when traditional and shadow banks coexist such that $\gamma$ falls within the range $0<\gamma<1$. In an interior equilibrium, banks are indifferent between shadow and traditional banking strategies such that (22) holds with equality

$$
E\left[\Pi^{S B}\right]=E\left[\Pi^{T B}\right]-\tau
$$

and may be interpreted as a free entry condition that determines $\gamma$ in equilibrium.

We proceed as follows in our description of the equilibrium solution: Section 3.2.1 builds up on the intuition provided about bank strategies above by discussing their interaction with fire-sales. We focus on fire-sales due to their role in creating strategic substitutabilities in banks' decision to enter shadow banking, which is crucial for bringing about an interior equilibrium. Section 3.2.2 then provides the conditions under which an interior equilibrium arises and discusses the implications of a rise in the costs of commitment and a deepening of secondary markets.

\subsubsection{Fire-sales and bank strategies}

There is a two-way interaction between fire-sales and bank strategies. On the one hand, entry into shadow banking increases the excess supply of assets in the secondary market and exacerbates fire-sales. ${ }^{23}$ On the other hand, fire-sales reduce the expected payoff from a shadow banking strategy relative to traditional banking and deter entry into the shadow banking sector.

Figure 8 demonstrates the mechanism behind this. As shown in Panel A, a fall in the secondary market price $P_{2}$ reduces shadow banks' liquidation value during an early withdrawal. This leads to an upward pivot in the deposit supply curve, raising shadow banks' funding costs and reducing the expected payoff from shadow banking.

\footnotetext{
${ }^{23}$ We use the phrases 'adopting a shadow banking strategy' and 'entry into shadow banking' interchangably.
} 
Figure 8: Fall in the secondary market price

Panel A: Shadow banking

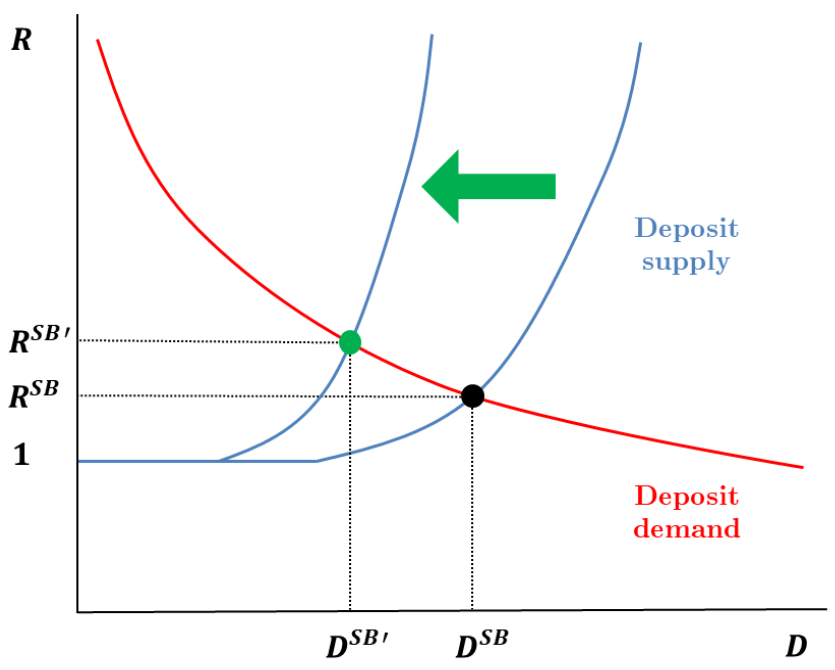

Panel B: Traditional banking

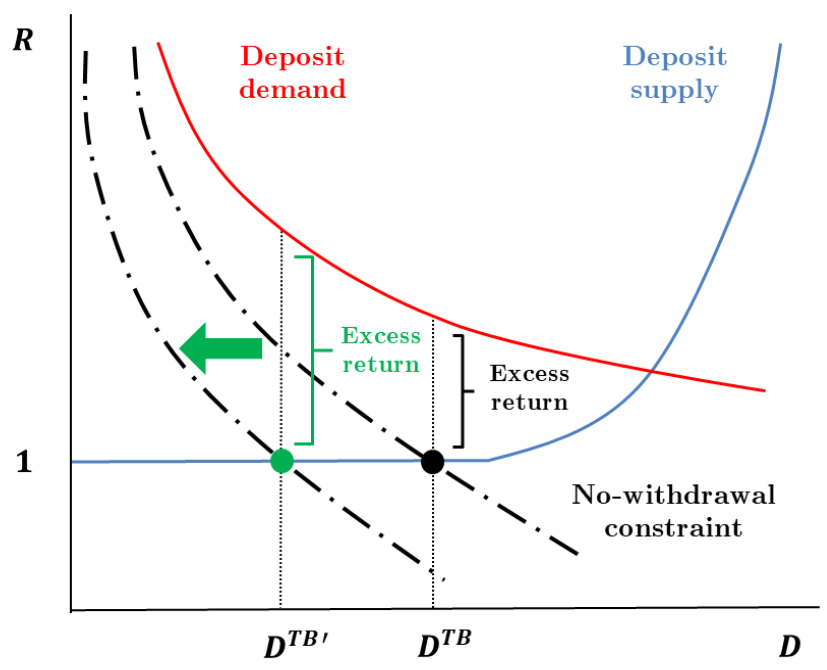

Note: The deposit demand curve is attained by combining (3) and (17). Deposit supply stems from (14) and (35). The no-withdrawal constraint is given by (21), (24), and (25).

In contrast, a fall in $P_{2}$ leads to a rise in the expected payoff from traditional banking. ${ }^{24}$ This is because it worsens the terms of trade between risky assets and cash after bad news, tightening the no-withdrawal constraint. As shown in Panel B, an inward shift in the constraint forces traditional banks to reduce investment $I_{1}$ in risky assets in the first period. Since traditional banks' funding costs remain at the risk-free rate, this increases the excess return and expected payoff from traditional banking.

These interactions constitute a fire-sale externality since banks do not internalize the impact of their entry into shadow banking on the profitability of other banks. Moreover, since profitability affects entry incentives, fire-sale externalities create strategic substitutabilities in banks' decisions to adopt a shadow banking strategy. As the shadow banking sector grows, the fire-sale discount on risky assets gets larger (i.e. $\phi$ falls), reducing the payoff from shadow banking relative to traditional banking until we reach an equilibrium sector size where banks are indifferent between the two strategies.

\subsubsection{Interior equilibrium}

Proposition 2 provides the conditions for an interior equilibrium. It shows that there will be an interior equilibrium when commitment costs fall within the range $\tau \in(\underline{\tau}, \bar{\tau})$.

\footnotetext{
${ }^{24}$ Strictly speaking, Lemma 2 indicates that a rise in profits occurs only in the region $P_{2}>\alpha \sigma_{h}$. This reflects two conflicting effects on traditional bank profits: a rise in the return from risky asset purchases in period 1 versus a fall in the quantity purchased. For $P_{2}>\alpha \sigma_{h}$, the former effect dominates and profits rise.
} 
Proposition 2 There is an interior equilibrium under the parameter restrictions $\mu \leq \bar{\mu}, \quad \phi \in$ $(\underline{\phi}, \bar{\phi}), \alpha<0.5, p<1-\alpha$ and $\tau \in(\underline{\tau}, \bar{\tau})$ where

$$
\begin{aligned}
& \underline{\tau} \equiv \begin{cases}\kappa\left[\frac{\sigma_{h}-1}{q}\left(\frac{1-(1-q) \sigma_{h}}{q}\right)^{\frac{\alpha}{1-\alpha}}-\frac{\mu}{1+\mu} \sigma_{h}\left(1-\frac{\mu}{1+\mu}(1-q) \sigma_{h}\right)^{\frac{\alpha}{1-\alpha}}\right] & \text { for } \mu<\frac{(p-q)\left(\sigma_{h}-1\right)}{\kappa p(1-q) \sigma_{h}-(p-q)\left(\sigma_{h}-1\right)} \\
\kappa\left(\sigma_{h}-\bar{\phi}\left[(1-p) \sigma_{h}+p \sigma_{l}\right]\right)\left(\bar{\phi}\left[(1-p) \sigma_{h}+p \sigma_{l}\right]\right)^{\frac{\alpha}{1-\alpha}} & \text { otherwise } \\
-\kappa \frac{\mu \sigma_{h}}{1+\mu}\left((1-q) \frac{\sigma_{h}}{1+\mu}+q \bar{\phi}\left[(1-p) \sigma_{h}+p \sigma_{l}\right]\right)^{\frac{\alpha}{1-\alpha}} & \text { for } \sigma_{h} \geq \frac{1}{1-q p(1-\alpha)}\end{cases} \\
& \bar{\tau} \equiv \begin{cases}\kappa\left(\sigma_{h}\right)^{\frac{1}{1-\alpha}}\left[(1-\alpha) \alpha^{\frac{\alpha}{1-\alpha}}-\frac{\mu}{1+\mu}\left(\frac{1-q}{1+\mu}+q \alpha\right)^{\frac{\alpha}{1-\alpha}}\right] & \text { otherwise } \\
\kappa\left[\frac{\sigma_{h}-1}{q p}\left(\frac{1-(1-q p) \sigma_{h}}{p q}\right)^{\frac{\alpha}{1-\alpha}}-\frac{\mu}{1+\mu} \sigma_{h}\left((1-q) \frac{\sigma_{h}}{1+\mu}+\frac{1-(1-q p) \sigma_{h}}{p}\right)^{\frac{\alpha}{1-\alpha}}\right]\end{cases}
\end{aligned}
$$

such that $\kappa \equiv(1-q)\left(A \alpha^{\alpha}\right)^{\frac{1}{1-\alpha}}, \bar{\tau}>\underline{\tau}>0$.

Proof. Provided in Appendix 2

Finally, we briefly discuss the properties of this equilibrium. In an interior equilibrium, the free entry condition (26) pins down the size of the shadow banking sector $\gamma$ and firesale discount $\phi$ through the interactions described in Section 3.2.1. Figure 9 illuminates the mechanism behind this by demonstrating the comparative statics of a rise in the commitment cost and a deepening of secondary markets under a numerical example.

Observe that the expected payoff schedule for traditional (shadow) banking is upward (downward) sloping in $\gamma$ in line with the intuition from Section 3.2.1. The equilibrium share of shadow banks is at the point where these two schedules intersect as per (26). We also plot this as a vertical bar along with the fire-sale schedule in order to deduce the equilibrium fire-sale discount.

Panel A shows that a rise in the cost of commitment $\tau$ causes a downward shift in the expected payoff schedule for traditional banking. At a given sector size $\gamma$, this makes shadow banking relatively profitable and leads to further entry into the sector. This in turn increases the excess supply of assets in the secondary market following bad news and exacerbates the fire-sale. Therefore, in equilibrium, a rise in the commitment cost increases the size of the shadow banking sector and the vulnerability of the economy to fire-sales.

Panel B shows the effects of an increase in the liquidity available in the secondary market due to a rise in the endowment of outside investors. At any given sector size $\gamma$, this reduces the fire-sale discount (i.e. a rise in $\phi$ ) bringing about an upward shift in the fire-sale schedule. Consequently, the expected payoff schedule for traditional (shadow) banking shifts down (up) in line with Section 3.2.1, and there is entry into shadow banking until the new schedules intersect at a larger sector size.

It is important to note that the fire-sale discount returns to its initial value at the new equilibrium. As such, a thicker secondary market for assets increases the size of the shadow banking 


\section{Figure 9: Numerical example}

A: Rise in commitment costs
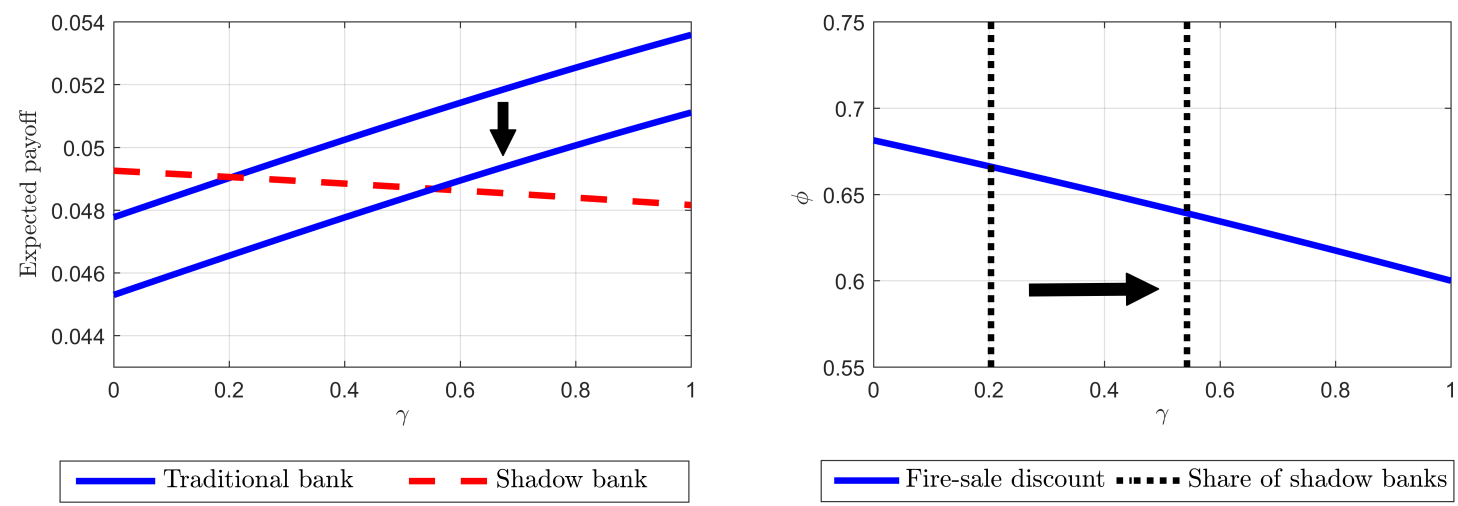

Traditional bank $\quad-$ Shadow bank

Fire-sale discount ...... Share of shadow banks

B: Thicker secondary markets
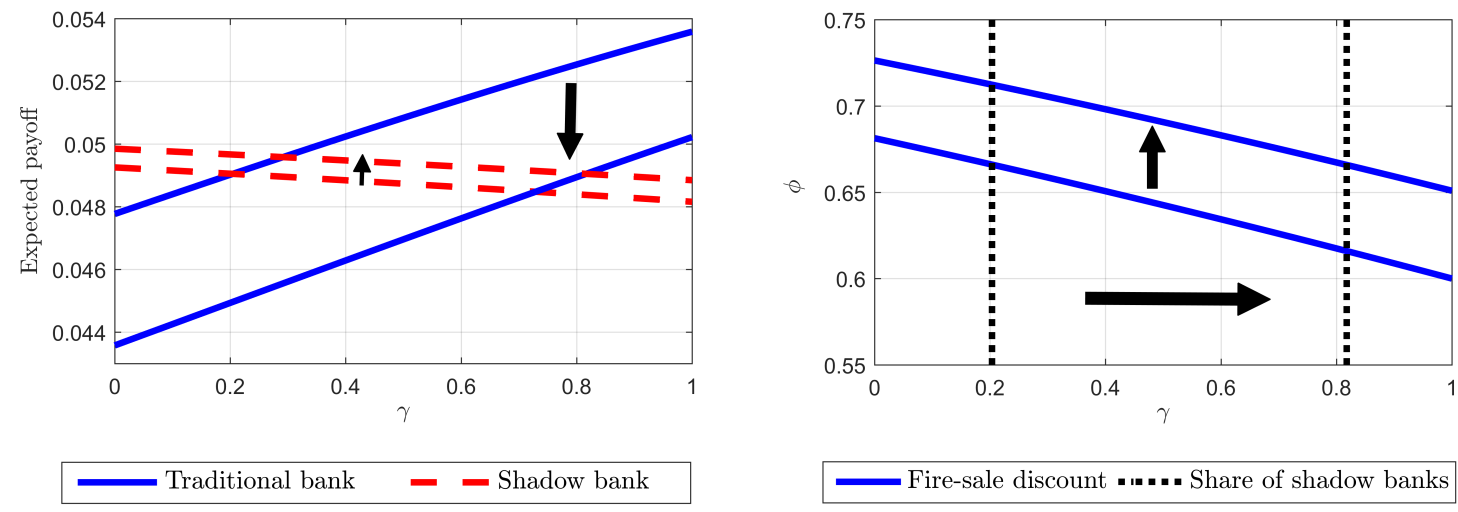

Note: The numerical example correponds to the calibration $A=1, \alpha=1 / 3, q=p=\sigma_{l}=1 / 2, \mu=\bar{\mu}$, and $\tau=0.0825$. We parameterize the fire-sale function $f($.$) according to Appendix \mathrm{H}$ and calibrate $\widetilde{E}$ to get $\underline{\phi}$ as a lower bound and set $\kappa=10\left((1-p) \sigma_{h}+p \sigma_{l}\right)^{-1}$. Panel A and B respectively display the effects of a small rise in $\tau$ and $\widetilde{E}$.

sector but does not alleviate the fire-sale. This finding stems from an essential property of the interior equilibrium: the fire-sale discount is implicitly determined by the free entry condition (26). Note that these results also apply to policy interventions aimed at alleviating fire-sales such as asset purchases and bailouts of financial institutions that would have contributed to the excess supply of assets. We analyze policy interventions in greater detail in Section 6 .

\section{A model with liquidity risk}

In this section, we extend the simple model to a setting with liquidity risk and a richer asset space. We introduce liquidity risk by allowing for the possibility of bank-runs as in Diamond and Dybvig (1983). Bank-runs are distinct from early withdrawals in that they are driven by self-fulfilling expectations in the presence of a liquidity shortfall $(\theta<1)$ in bank balance sheets, 
rather than an optimal response to bad news.

We also expand the asset space to allow for three different asset types, liquid, safe, and risky, which we respectively denote with $(\lambda, s, r)$. The risky asset is identical to the (non-cash) asset in the simple model. The safe and liquid assets both yield a unit payoff with certainty, but they differ in that the safe asset matures in period 3 while the liquid asset yields its payoff in period 2 .

The richer asset space serves two purposes. First, it allows us to consider the conditions under which safe assets are endogenously liquid due to secondary markets. A priori, it is not clear whether safe assets would be subject to a fire-sale since purchases by traditional banks (which re-allocate their portfolios towards safe assets) may offset sales by shadow banks.

Second, a richer asset space permits us to consider the interplay between fire-sales, market discipline, and liquidity risk. On the one hand, without a fire-sale on safe assets, portfolio re-allocation required to satisfy the no-withdrawal constraint increases traditional banks' liquidation values $\left(\theta^{T B}=1\right)$ and reduces their vulnerability to bank-runs. On the other hand, when there is a fire-sale on safe assets, liquidity risk leads to a rise in bank funding costs and undermines market discipline such that traditional banks may also take on solvency risk.

In the interest of brevity, we only describe the aspects of the model that differ from Section $3 .^{25}$ The remainder of the section is organized as follows: Section 4.1 provides further details about bank-runs. Section 4.2 extends secondary markets and outside investors to a framework with multiple assets. Finally, Section 4.3 presents analytical results pertaining to the relationship between the fire-sale on safe assets, market discipline, and liquidity risk.

\subsection{Bank-runs}

When a bank has a liquidity shortfall $\theta<1$, sequential service in withdrawals leads to the emergence of a bank-run equilibrium where households find it optimal to withdraw their deposits given that everyone else is withdrawing. We resolve this multiplicity with the use of sunspots. Specifically, we let $\varepsilon_{\xi}$ be be a random variable drawn from a uniform distribution on the unit interval at the beginning of period 2 and $\bar{\xi} \in[0,1]$ a constant threshold. When $\varepsilon_{\xi} \leq \bar{\xi}$, household sentiments coordinate on a bank-run. Provided that there is a liquidity shortfall, these sentiments become self-fulfilling and the bank suffers from a run. Since $\varepsilon_{\xi}$ is uniformly distributed on a unit interval, the probability of a bank run is then simply given by

$$
\xi=\left\{\begin{array}{l}
0 \text { for } \theta=1 \\
\bar{\xi} \text { for } \theta<1
\end{array}\right.
$$

\footnotetext{
${ }^{25}$ See Appendix I for a complete specification of the model.
} 
Only traditional banks are affected by bank-runs as there is no liquidity shortfall after good news and shadow banks face an early withdrawal after bad news. ${ }^{26}$ Moreover, we assume that the sunspot realization is idiosyncratic to each bank such that $\xi$ may be interpreted as the share of traditional banks liquidated in a bank-run. ${ }^{27}$

Finally, note that it is straightforward to introduce a more sophisticated specification for the bank-run probability. We adopt this simple framework as it permits us to isolate the role of banks' portfolio strategies and fire-sales in bringing about a liquidity shortfall in the first place. In Appendix J, we approximate the global games solution of Goldstein and Pauzner (2005) by depicting $\bar{\xi}$ as a negative function of the liquidation value $\theta$. The qualitative results from our mechanism remain the same.

\subsection{Secondary market}

We extend the secondary market described in Section 3.1.2 to a framework with multiple assets. Since the liquid asset yields its payoff in period 2, only safe and risky assets are traded in the secondary market. The excess supply of each asset is given by the expressions

$$
\widetilde{I}(i)=\gamma I_{1}^{S B}(i)+(1-\gamma)\left(I_{1}^{T B}(i)-(1-\xi) I_{2}^{T B}(i)\right) \geq 0 \forall i \in\{s, r\}
$$

and sold to a common set of risk neutral outside investors.

Outside investors allocate their endowment $\widetilde{E}$ between purchases of safe and risky assets and an outside project $\widetilde{K}$ that yields a safe payoff $g(\widetilde{K})$ where $g^{\prime}()>0,. g^{\prime \prime}()<$.0 . Their first order conditions indicate that there is a common fire-sale discount $\phi \in[0,1]$ for the two assets, and it is defined implicitly by the expression

$$
\phi=\frac{1}{g^{\prime}\left(\widetilde{E}-\phi\left[(1-p) \sigma_{h}+p \sigma_{l}\right] \widetilde{I}(r)-\phi \widetilde{I}(s)\right)}
$$

which suggests that a rise in the total excess supply of safe and risky assets leads to a decrease in $\phi$. Crucially, however, an asset type is only subject to the fire-sale discount when it is in excess supply such that its marginal buyer is an outside investor. Therefore, secondary market

\footnotetext{
${ }^{26}$ To be precise, we assume that early withdrawals and bank-runs take place simultaneously so that there is no need to consider the bank run equilibrium for shadow banks.

${ }^{27}$ This assumption streamlines the exposition by preventing the outcome in the second period from diverging between bank-run and no bank-run. With an aggregate sunspot, uncertainty would immediately be resolved in the bank-run equilibrium. The non-bank run equilibrium would only differ from the equilibrium considered here in that the excess supply of assets in the secondary market would be somewhat lower.
} 
prices depend on an asset's own excess supply such that

$$
\begin{aligned}
& P_{2}(s)=\left\{\begin{array}{lr}
1 & \text { for } \widetilde{I}(s)=0 \\
\phi & \text { otherwise }
\end{array}\right. \\
& P_{2}(r)=\left\{\begin{array}{lr}
(1-p) \sigma_{h}+p \sigma_{l} & \text { for } \widetilde{I}(i) \leq 0 \\
\left.\phi\left[(1-p) \sigma_{h}+p \sigma_{l}\right]\right] & \text { otherwise }
\end{array}\right.
\end{aligned}
$$

\subsection{Analytical results}

Proposition 3 shows that the fire-sale on safe assets plays a definitive role in shaping the relationship between market discipline and liquidity risk.

Proposition 3 In equilibrium, traditional banks commit to a minimum recovery rate

$$
\bar{V}=1-\frac{q}{p} \frac{\xi\left(1-\theta^{T B}\right)}{1-q\left(1-\xi\left(1-\theta^{T B}\right)\right)}
$$

and the interest rate on their deposits is given by

$$
R^{T B}=1+\frac{q}{1-q} \xi\left(1-\theta^{T B}\right)
$$

With $P_{2}(s)=1$, traditional banks have a liquidation value $\theta^{T B}=1$. This leads to $\xi=0$ and (28), (29) yield

$$
\bar{V}=R^{T B}=1
$$

With sufficiently low $P_{2}(s)<1$, traditional banks have a liquidity shortfall $\theta^{T B}<1$ which leads to $\xi>0$. (28), (29) then yield

$$
\bar{V}<1<R^{T B}
$$

Proof. Provided in Appendix G

When there is no fire-sale on safe assets such that $P_{2}(s)=1$, satisfying the no-withdrawal constraint

$$
\sigma_{l} I_{2}^{T B}(r)+I_{2}^{T B}(s) \geq \bar{V} R^{T B} D^{T B}
$$

leads to a liquidation value

$$
\theta^{T B}=\min \left[1, \frac{P_{2}(r) I_{2}^{T B}(r)+P_{2}(s) I_{2}^{T B}(s)}{D^{T B}}\right]=1
$$

since risky assets never trade at a price below their payoff under weak fundamentals $\left(P_{2}(r) \geq\right.$ $\sigma_{l}$ ). This in turn eliminates the possibility of bank-runs such that $\xi=0$. Without liquidity 
risk, market discipline through the threat of an early withdrawal ensures that there is also no solvency risk $(\bar{V}=1)$ and traditional banks collect deposits at the risk-free rate as in Section 3.1.3.

With a sufficiently large fire-sale on safe assets, on the other hand, traditional banks have a liquidity shortfall $\left(\theta^{T B}<1\right)$ despite satisfying the no-withdrawal constraint. This leaves traditional banks vulnerable to bank-runs and creates a vicious cycle between rising deposit interest rates and solvency risk. Households anticipate that they may not be repaid fully in the event of a bank run and demand higher deposit rates as compensation. The rise in deposit rates in turn weakens the threat of early withdrawal as households stand to lose more in terms of interest foregone. This leads to a decline in the minimum recovery rate $\bar{V}$, allowing traditional banks to take on solvency risk. Finally, the increase in solvency risk brings about a further rise in deposit rates and completes the vicious cycle.

In the next section, we present numerical results that highlight the role of a large shadow banking sector in causing a fire-sale on safe assets, which leaves traditional banks illiquid and undermines market discipline through the mechanism described above.

\section{$5 \quad$ Numerical results}

This section provides numerical results from the model with liquidity risk. It proceeds as follows: Section 5.1 describes the calibration which targets the United States over the recent financial crisis. Section 5.2 presents and discusses the results from a numerical simulation.

\subsection{Calibration}

Table 2 reports the calibrated parameters. The payoff of risky asset under weak fundamentals is set to $\sigma_{l}=0.21$ in line with the average recovery rate from junior debt and $\sigma_{h}$ is backed out using the normalization of expected payoffs given in (1). ${ }^{28}$ The probabilities $(q, p)$ are calibrated to the frequency of recessions and deep recessions (conditional on a recession) in the United States. $^{29}$

Regarding the entrepreneurs, we calibrate the output elasticity of capital to the standard Cobb-Douglas value $\alpha=1 / 3$ and normalize productivity to $A=1$. For the mark-up, we adopt a parameterization that approximates monopolistic competition

$$
\mu=v \frac{1-\alpha}{\alpha}
$$

\footnotetext{
${ }^{28}$ Security classes which have less seniority than $70 \%$ of total liabilities are senior to it are defined as junior.

${ }^{29}$ We use business cycle data from the NBER which covers the period December 1854-June 2017 at a monthly frequency. We label as 'deep recessions' the contractionary episodes of 1873-79 (the Long Depression), 1929-33 (the Great Depression), and 2008-09 (the Great Recession).
} 
Table 2: Calibration

\begin{tabular}{|c|c|c|c|}
\hline Parameter & Value & Description & Source \\
\hline \hline$\sigma_{l}$ & 0.21 & Low payoff from risky assets & Moody's Investors Service (2007) \\
$q$ & 0.41 & Prob. of bad news & NBER \\
$p$ & 0.22 & Prob. of weak fundamentals & NBER \\
$\alpha$ & 0.33 & Cobb-Douglas parameter & - \\
$A$ & 1.00 & Productivity & - \\
$\mu$ & 0.18 & Mark-up & World Bank \\
$\widetilde{E}$ & 2.80 & Outside investor endowment & Moody's, Federal Reserve Board \\
$z$ & 10.0 & Outside investment parameter & Moody's, Federal Reserve Board \\
$\bar{\xi}$ & 0.15 & Bank-run probability & Federal Reserve Bank of St. Louis \\
$\tau$ & 0.11 & Commitment cost & Financial Stability Board (2017) \\
\hline
\end{tabular}

where $v \in[0,1]$ represents banks' market share. We then calibrate the mark-up to a value consistent with the 5-bank asset concentration in the United States over 2007-2010.

In the secondary market, we parameterize the payoff function for outside investments to $g(\widetilde{K})=z^{-1} \ln (\widetilde{K})$ where $z$ is a constant such that (27) becomes

$$
\phi=\frac{z \widetilde{E}}{1+\kappa\left[\left((1-p) \sigma_{h}+p \sigma_{l}\right) \widetilde{I}(r)+\widetilde{I}(s)\right]}
$$

Our calibration strategy for $(\widetilde{E}, z)$ targets the rise in the yield spreads between AAA-rated seasoned corporate bonds and the effective Federal Funds Rate during the financial crisis. Specifically, we back out a percentage decline in bond prices $\Delta \hat{P} / \hat{P}$ from the difference between the peak spread in November 2008 and the average spread for the pre-crisis period between January 2016 and June 2017. We then calibrate $(\widetilde{E}, z)$ to generate an equilibrium fire-sale discount that matches the decline in the price of safe assets under bad news to $\Delta \hat{P} / \hat{P}^{30}$

Similarly, the calibration for the bank-run probability $\bar{\xi}$ targets TED spreads at the peak of the financial crisis. To do this, we construct a hypothetical interest rate for traditional bank deposits collected after bad news but before the realization of bank-runs. With risk neutral households, this is given by

$$
R_{2}^{T B}=\frac{1}{1-\bar{\xi}} \frac{1-\bar{\xi} \theta^{T B}}{1-p(1-\bar{V})}
$$

\footnotetext{
${ }^{30}$ Since $P_{1}(s)$ is bank-specific and best interpreted as origination costs in the absence of first period asset trade, our measure for the decline in safe asset prices refers to $P_{2}(s)$ relative to their expected payoff 1 .
} 
and we calibrate $\bar{\xi}$ to match $R_{2}^{T B}$ to the average TED spread in the last quarter of $2008 .{ }^{31}$

Finally, the calibration for the commitment cost $\tau$ targets the pre-crisis ratio of shadow bank assets to total bank assets, which is approximately 63\%. Accordingly, we set $\tau=0.11$ which amounts to just below $7 \%$ of the value of a traditional bank's assets in period 1 .

\subsection{Results}

Figure 10 plots the numerical solution across a range $\gamma \in[0,1]$ of shadow banking sector sizes. The equilibrium sector size is denoted by the vertical bar labelled $\gamma^{*}$ where traditional and shadow banking strategies yield the same expected payoff. The first panel of Figure 10 indicates that there is a unique and globally stable interior equilibrium where shadow and traditional banks coexist. This reflects the strategic substitutabilities between banking strategies described in Section 3.2.

Entry into shadow banking exacerbates the fire-sale after bad news (see Panel 2). This increases the interest rates on shadow bank deposits (see Panel 4) and reduces the expected payoff from shadow banking. In contrast, traditional bank profits rise as the fire-sale increases the excess return from the binding no-withdrawal constraint. Therefore, the shadow banking sector grows until banks are indifferent between the two strategies at the equilibrium sector size $\gamma^{*}$.

The bar labelled $\bar{\gamma}$ denotes the threshold sector size above which safe assets suffer from a fire-sale. Under our calibration, high commitment costs lead to $\gamma^{*}>\bar{\gamma}$ such that there is a fire-sale on safe assets in equilibrium. Panel 3 shows that this reduces the liquidation value of traditional banks, leaving them vulnerable to bank-runs. As explained in Section 4.3, liquidity risk increases deposit rates $R^{T B}$ (see Panel 4) and undermines market discipline on traditional banks. Accordingly, Panel 5 shows that the minimum recovery rate $\bar{V}$ declines below full repayment for $\gamma>\bar{\gamma}$ such that traditional banks have insolvency risk in equilibrium.

Note that, with lower commitment costs, the expected payoff from traditional banking is higher at all sector sizes such that we may have a smaller shadow banking sector $\gamma^{*} \leq \bar{\gamma}$ in equilibrium and no fire-sale on safe assets. ${ }^{32}$ Panel 3 shows that traditional banks would then have no liquidity shortfall and hence no vulnerability to bank-runs. Without liquidity risk, traditional banks borrow at the risk-free rate and the no-withdrawal constraint imposes market discipline with $\bar{V}=1$ such that traditional banks have no solvency risk either.

Panel 6 shows the evolution of shadow and traditional bank deposits across $\gamma$. As $\gamma$ rises and the fire-sale deepens, shadow banks respond to the rise in their funding costs by reducing

\footnotetext{
${ }^{31}$ See Figure 4 for the evolution of TED spreads. We use TED spreads instead of spreads on deposit rates to exclude the effects of deposit insurance guarantees. Note also that (32) is conditional on a liquidity shortfall, which is the case in equilibrium.

${ }^{32}$ See Figure 9 for the comparative statics of the commitment cost and fire-sale discount in the simple model.
} 
Figure 10: Numerical results
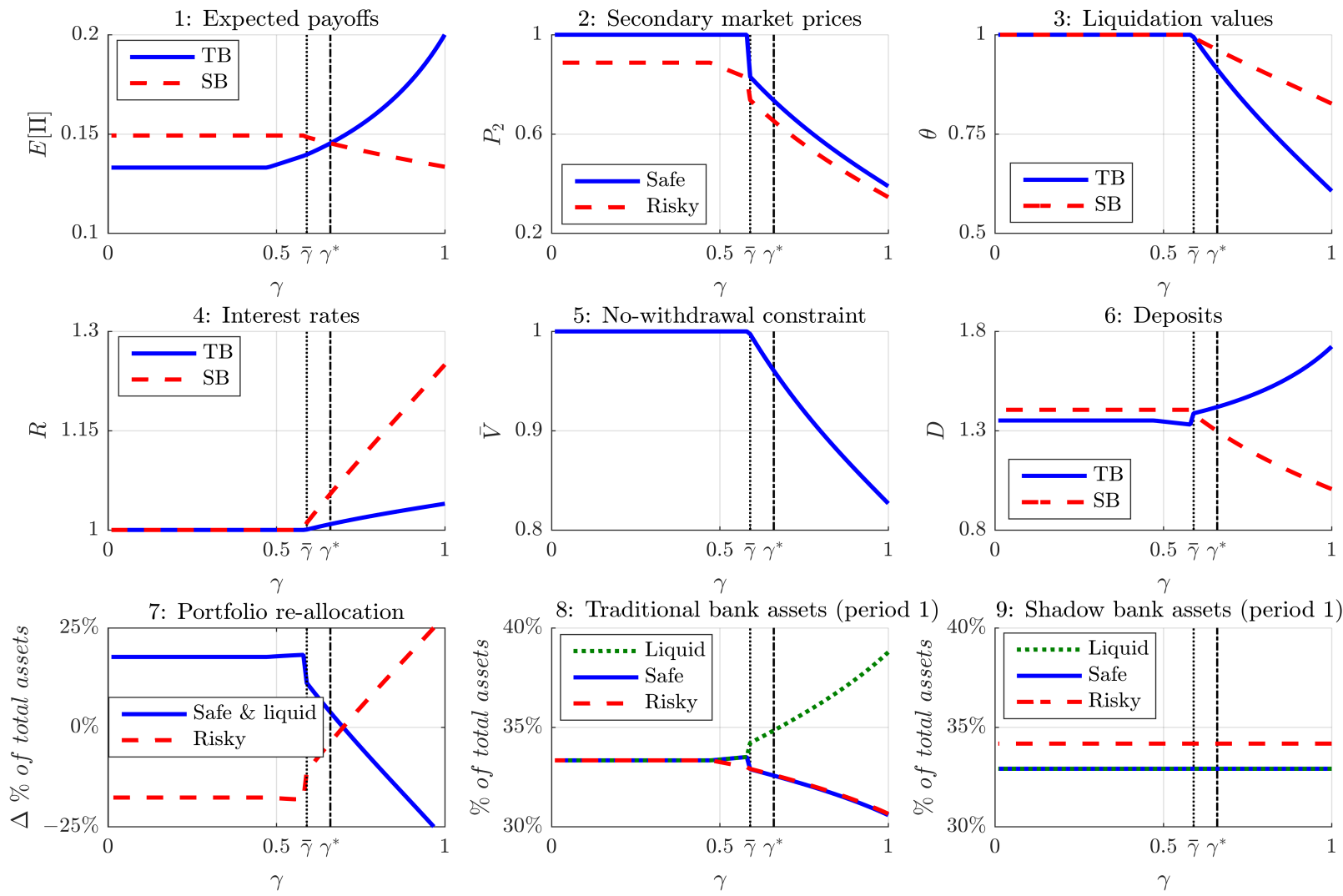

Note: Expected payoffs are inclusive of the commitment cost $\tau$. Total assets in period 1 and 2 are respectively defined as $\bar{I}_{1} \equiv \sum_{i \in\{\lambda, s, r\}} I_{1}(i)$ and $\bar{I}_{2} \equiv \sum_{i \in\{s, r\}} P_{2}(i) I_{2}(i)$. Panel 7 plots $\left(\bar{I}_{2}^{T B}\right)^{-1} P_{2}(s) I_{2}^{T B}(s)-$ $\left(\bar{I}_{1}^{T B}\right)^{-1} \sum_{i \in\{\lambda, s\}} I_{1}^{T B}(i)$ for safe and liquid assets, and $\left(\bar{I}_{2}^{T B}\right)^{-1} P_{2}(r) I_{2}^{T B}(r)-\left(\bar{I}_{1}^{T B}\right)^{-1} I_{1}^{T B}(r)$ for risky assets. Panel 8 plots $I_{1}^{T B}(i) / \bar{I}_{1}$ respectively for $i=\{\lambda, s, r\}$ and Panel 9 does the same for shadow banks.

their deposits. Traditional banks, on the other hand, expand their balance sheets due to the relaxation of the no-withdrawal constraint. This is consistent with observations in Fact 1 of Section 2 which indicate that traditional bank balance sheets expanded at a faster rate in 200207 when the shadow banking sector was growing rapidly than in 2008-15 when the shadow banking sector was stagnant. ${ }^{33}$

Panel 7 demonstrates portfolio re-allocation by traditional banks after bad news. When the shadow banking sector is small and market discipline intact, traditional banks re-allocate up to $18 \%$ of their portfolio from risky assets to safe and liquid assets in order to prevent an early withdrawal. As the shadow banking sector grows and market discipline is undermined, traditional banks reduce the extent of their re-allocation away from risky assets and eventually the direction is reversed. In equilibrium, there is a re-allocation of approximately $4 \%$ away from

\footnotetext{
${ }^{33}$ Note that, although Panel 6 indicates that, in equilibrium, an individual traditional bank has a larger balance sheet than an individual shadow bank, this does not contradict Figure 1, which is at the aggregate level. In fact, we calibrate $\tau$ to target the ratio of shadow bank assets to traditional bank assets in 2007 .
} 
risky assets. Compared to the observations in Fact 4 of Section 2, this predicts the direction of portfolio re-allocation correctly, but falls somewhat short of the observed amount of $6 \%$ to $8 \%$ (see Figure 4). It is possible that this discrepancy reflects the impact of macroprudential regulation and additional liquidity provided by the Federal Reserve.

Finally, Panels 8 and 9 display the investment strategies of traditional and shadow banks in period 1. When there is no fire-sale on safe assets $(\gamma<\bar{\gamma})$, market discipline imposed by the no-withdrawal constraint forces traditional banks to behave as if they internalize asset payoffs under weak fundamentals. Therefore, they devote an equal share of their investment to each asset type. In response to a fire-sale on safe assets, traditional banks increase their holdings of liquid assets to prop up their liquidation value. While this increases the funds available to them after bad news, their reaction is not strong enough to keep them solvent under weak fundamentals because of the decline in the minimum recovery rate $\bar{V}$ (as shown in Panel 5).

Shadow banks, on the other hand, skew their investment towards risky assets since they only internalize the states after good news due to limited liability. Without the ability to commit, they also take their borrowing costs $R^{S B}$ as given and hence do not change their asset composition in response to fire-sales.

\section{$6 \quad$ Policy analysis}

In this section, we consider policy interventions aimed at fostering financial stability. The numerical results in Section 5.2 demonstrate that, with sufficiently high commitment costs, the shadow banking sector expands to a size that is systemically risky in the sense that its collapse gives rise to both liquidity and solvency risk for traditional banks.

We consider three distinct interventions that aim to offset this. Section 6.1 considers asset purchases in the secondary market. Section 6.2 evaluates interventions to secure the traditional banking sector such as liquidity support, deposit insurance guarantees and macroprudential regulation. Finally, Section 6.3 proposes a tax on shadow bank profits.

\subsection{Asset purchases}

The government may lean against fire-sales by purchasing assets in the secondary market. In the interest of simplicity, we consider an intervention that purchases solely safe assets such that their excess supply becomes

$$
\widetilde{I}(s)=\gamma I_{1}^{S B}(s)+(1-\gamma)\left(I_{1}^{T B}(s)-(1-\xi) I_{2}^{T B}(s)\right)-I^{A P}
$$


Figure 11: Asset purchases
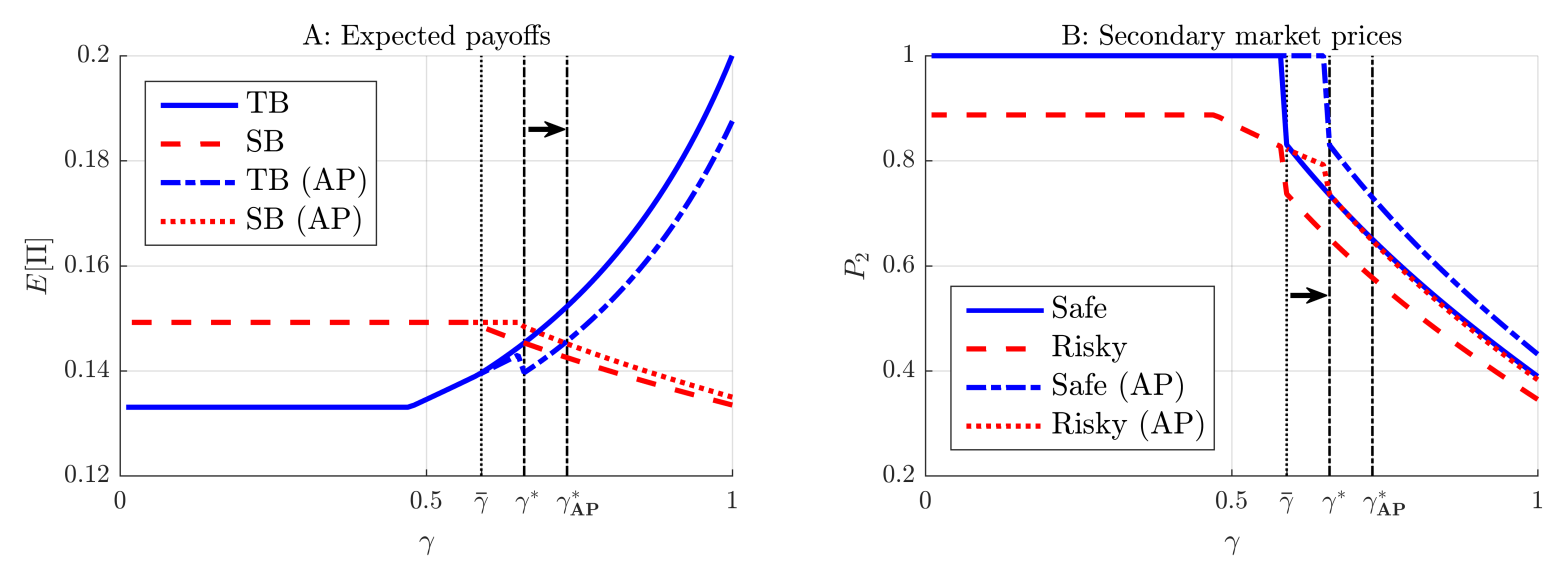

Note: Expected payoffs are inclusive of the commitment cost $\tau$. AP refers to the outcome under asset purchases.

where $I^{A P}>0$ refers to asset purchases by the government. ${ }^{34}$ Figure 11 shows the outcome of an intervention that aims to eliminate the fire-sale on safe assets by setting $I^{A P}$ to absorb their excess supply at the equilibrium sector size $\gamma^{*}$.

The outcome of this intervention is identical to the deepening of secondary markets considered in Section 3.2.2. It reduces the fire-sale discount (i.e. increases $\phi$ ) at any given sector size and is successful in eliminating the fire-sale on safe assets at the initial equilibrium $\gamma^{*}$. In other words, the intervention shifts the fire-sale threshold $\bar{\gamma}$ to $\gamma^{*}$ (see Panel B). However, by alleviating the fire-sale, the intervention also reduces the funding costs of shadow banks and increases the expected payoff from shadow banking relative to traditional banking (see Panel A). This leads to entry into the shadow banking sector until we reach the new equilibrium sector size $\gamma_{A P}^{*}>\gamma^{*}$.

It is not a coincidence that in the new equilibrium $\gamma_{A P}^{*}$, the fire-sale discount (and all variables other than the sector size) takes the same value as in the initial equilibrium $\gamma^{*}$. This is because, as explained in Section 3.2.1, the fire-sale discount is implicitly determined by the free entry condition (26). Our analysis then leads to a crucial insight: policy interventions in secondary markets are ineffective when there is free entry into shadow banking. This is also true in the opposite direction. For example, a tax on secondary market transactions deepens the fire-sale and reduces shadow bank profits at a given sector size, but both of these effects are reversed by exit from the shadow banking sector.

Finally, is important to stress that entry into shadow banking is driven by the ex-ante anticipation of asset purchases. In period 2, the size of the shadow banking sector is already determined and a surprise asset purchase scheme would be successful in alleviating the fire-sale

\footnotetext{
${ }^{34}$ Allowing for risky asset purchases leads to no discernible changes in the results.
} 
on safe assets and reducing both liquidity and solvency risk. This may potentially lead to time inconsistency issues as policymakers would naturally find it tempting to intervene once the fire-sale is underway.

\subsection{Interventions to secure traditional banks}

Recall from Fact 4 in Section 2 that traditional bank liabilities sharply increased in the second half of 2008. This increase was driven by Federal Reserve funding and a rise in deposits protected by deposit insurance guarantees. In this section, we show that interventions of this form may effectively ringfence the traditional banking sector from the financial instability caused by shadow banks. In equilibrium, these interventions increase the size of the shadow banking sector but have a net positive impact on financial stability.

To begin with, we consider a liquidity provision scheme that permits traditional banks to borrow $L$ from the central bank at the risk-free rate in the second period. The liquidation value of traditional banks can then be written as

$$
\theta^{T B}=\min \left[1, \frac{P_{2}(r) I_{1}^{T B}(r)+P_{2}(s) I_{1}^{T B}(s)+I_{1}(\lambda)+L}{D^{T B}}\right]
$$

and two conditions must be satisfied for liquidity provision to eliminate both solvency and liquidity risk. First, the amount of liquidity provided should be sufficient to offset liquidity shortfalls such that

$$
L \geq \underline{L} \equiv D^{T B}-P_{2}(r) I_{1}^{T B}(r)-P_{2}(s) I_{1}^{T B}(s)-I_{1}(\lambda)
$$

This eliminates the possibility of bank-runs $(\xi=0)$ and liquidity risk.

Second, liquidity borrowed from the central bank should be fully collateralized. ${ }^{35}$ This rules out default on the central bank and makes depositors effectively junior to the central bank. The no-withdrawal constraint then becomes

$$
\sigma_{l} I_{2}^{T B}(r)+I_{2}^{T B}(s) \geq L+\bar{V} D^{T B} R^{T B}
$$

such that market discipline is not adversely affected by liquidity provision. The results from Proposition 3 then follow through: in the absence of liquidity risk, the threat of an early withdrawal eliminates solvency risk $(\bar{V}=1)$ and interest rates on traditional bank deposits fall to the risk-free rate $\left(R^{T B}=1\right)$.

Figure 12 shows the equilibrium outcome under liquidity provision in comparison to the baseline results in Section 5.2. Panel B shows that, in addition to ringfencing the traditional

\footnotetext{
${ }^{35}$ This places an upper bound on the amount of liquidity provided $L \leq \bar{L}=\sigma_{l} I_{2}^{T B}(r)+I_{2}^{T B}(s)$ where $\bar{L} \geq \underline{L}$.
} 
Figure 12: Liquidity Provision
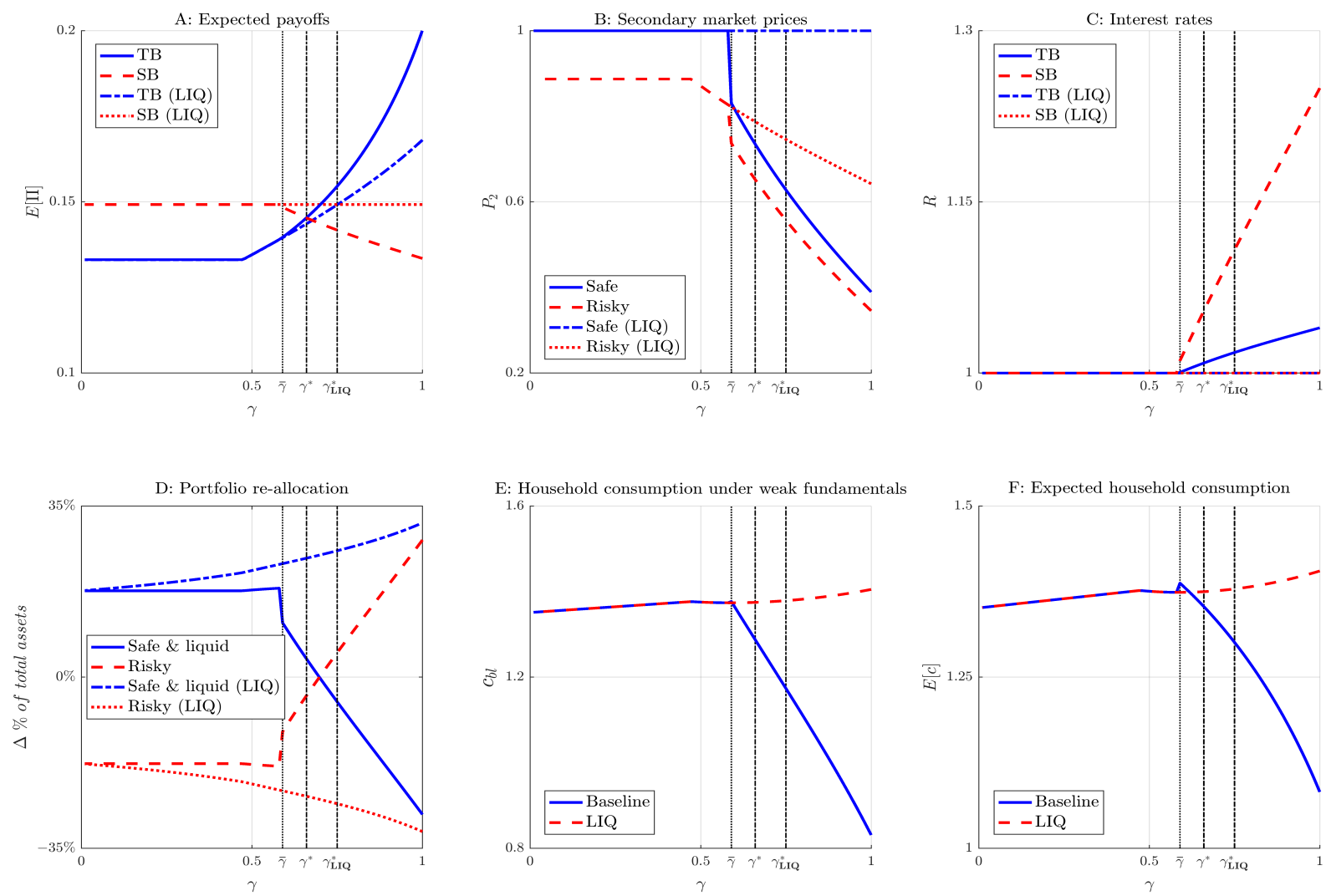

Note: Expected payoffs are inclusive of the commitment cost $\tau$.

banking sector, liquidity provision eliminates the fire-sale on safe assets. This is because, with $P_{2}(s)<1$, traditional banks take advantage of an arbitrage opportunity by borrowing from the central bank at the risk-free rate and purchasing safe assets at a discount. ${ }^{36}$ They continue to do this until there is no excess supply of safe assets such that $P_{2}(s)=1$. Panel D shows that these purchases also increase the extent of portfolio reallocation towards safe and liquid assets.

By alleviating the fire-sale, liquidity provision indirectly reduces the funding costs of shadow banks. This in turn increases the expected payoff from shadow banking, leading to further entry into the sector (see Panel A) and increases its size in equilibrium. However, this does not have any adverse effects on traditional banks.

Without explicitly conducting welfare analysis, we also find it worth pointing out that, in equilibrium, liquidity provision increases household consumption both under weak fundamentals (Panel E) as well as in terms of its unconditional (period 1) expectation (Panel F). ${ }^{37}$ This is because, by preventing the fire-sale on safe assets, the intervention alleviates the destabilizing

\footnotetext{
${ }^{36}$ This arbitrage opportunity is not present in the baseline model. Without liquidity provision or deposit insurance guarantees, traditional banks may only collect funds in the second period by offering interest rates $R_{2}^{T B}>1$ given by (32). They find it prohibitively costly to do so.

${ }^{37}$ We do not conduct welfare analysis due to the stylized nature of our model.
} 


\section{Figure 13: Tax on shadow bank profits}

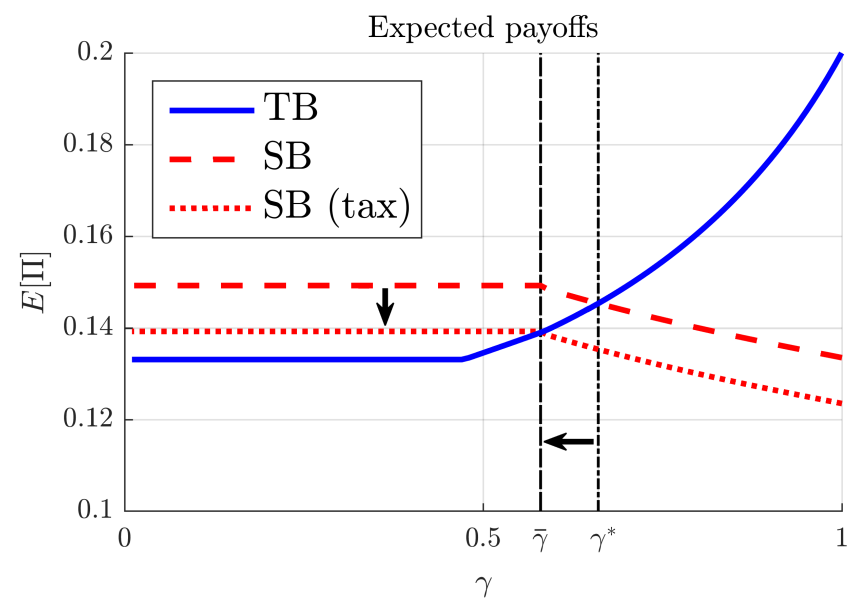

Note: Expected payoffs are inclusive of the commitment cost $\tau$ and $\operatorname{tax} T$.

impact of the expansion in shadow banking. Therefore, the gains from securing the traditional banking sector are not offset by the rise in the size of the shadow banking sector.

Finally, note that the exact same outcome may be achieved by combining deposit insurance guarantees with bank regulation that imposes a minimum recovery rate $\bar{V}=1$. This intervention differs from (collateralized) liquidity provision only with respect to the role of market discipline. As explained above, liquidity provision is designed to take advantage of market discipline while securing traditional banks from liquidity risk. In contrast, eliminating liquidity risk through deposit insurance also removes the no-withdrawal constraint on traditional banks since depositors never stand to take a loss. Market discipline must then be replaced with bank regulation to prevent risk-shifting.

\subsection{Tax on shadow bank profits}

The last policy intervention we consider is the taxation of shadow bank profits with the purpose of deterring entry into the sector. This can be considered as a Pigouvian tax since entry into shadow banking imposes a negative externality on the remainder of the financial sector through its contribution to fire-sales. We consider a constant tax $T$ such that the free entry condition becomes

$$
E\left[\Pi^{S B}\right]-T=E\left[\Pi^{T B}\right]-\tau
$$

Figure 13 shows the outcome under a tax level $0<T<\tau$ that reduces the equilibrium sector size of shadow banks to the fire-sale threshold $\bar{\gamma}$. Panel A shows that the tax shifts down the expected payoff schedule for shadow banking and brings about an equilibrium without a firesale on safe assets. Since this is a tax on profits, the equilibrium allocation at any given sector 
size $\gamma$ is identical to the numerical results in Figure 10. Therefore, reducing the equilibrium sector size to $\bar{\gamma}$ eliminates liquidity risk in the traditional banking sector which strengthens market discipline such that there is also no solvency risk.

Note that the effect of a tax on shadow banks is equivalent to a decrease in the commitment $\operatorname{cost} \tau$. Therefore, when taxing shadow banks is not feasible, the same outcome can also be achieved with a transfer to traditional banks. ${ }^{38}$ Alternatively, shadow bank profits may be reduced indirectly with a tax on their liabilities $D^{S B}$. In a less stylized set up, this would correspond to a tax on the funding instruments most widely used by shadow banks such as ABCPs.

\section{Conclusion}

We have presented a model of the financial sector in which shadow banking emerges endogenously as an alternative banking strategy. A key aspect of the model is that depositors reoptimize in response to revisions in expectations about asset returns. To prevent early withdrawals by their depositors, traditional banks optimally commit to a safe portfolio strategy while shadow banking strategies combine high risk-taking with the prospect of an early liquidation after bad news.

Two important insights emerge as a consequence. First, costly commitment and fire-sale externalities bring about an equilibrium where ex-ante identical banks optimally cluster into shadow and traditional banking strategies. The size of the shadow banking sector increases in the cost of commitment and the availability of liquidity in the secondary market. Second, when the shadow banking sector is large, the liquidation of shadow banks leave traditional banks susceptible to liquidity risk. This increases deposit rates offered by traditional banks and weakens market discipline on them, engendering greater risk-taking and a rise in solvency risk.

The model also naturally provides novel insights for policy design. First, we show that policy interventions have significantly different implications when the adjustment on the size of the shadow banking sector is taken into account. Secondary market interventions, such as asset purchases by the government, are effective in alleviating the fire-sale ex-post, but their ex-ante expectation fuels further growth of the shadow banking sector in a manner that exactly offsets these gains. We conjecture that this may lead to time inconsistency issues for policymakers who may find it tempting to intervene once the fire-sale is underway.

Second, we find that policy interventions aimed at securing the traditional banking sector, similar to those implemented by the Federal Reserve during the 2008 financial crisis, also lead to

\footnotetext{
${ }^{38}$ Quantitatively, our model indicates that the necessary transfer amounts to $9 \%$ of commitment costs, which is equivalent to approximately $0.6 \%$ of the value of a traditional bank's portfolio in period 1 .
} 
an expansion in shadow banking when anticipated, but have a net positive impact on financial stability. Third, our findings regarding the destabilizing consequences of a large shadow banking sector lend support to taxation of shadow bank profits (or equivalently a transfer to traditional

banks) with the purpose of reducing the size of the shadow banking sector to a level compatible with financial stability.

Finally, it is worth noting that the mechanism considered in this paper is more general than its application to shadow banking and the 2008 financial crisis. In economies without credible deposit insurance guarantees and strict enforcement of banking regulation, financial intermediation strategies that combine high risk-taking with an unstable funding structure may exist within the commercial banking sector. One clear example of this is the United States during the National Banking Era of 1863-1914. In this period, there was no central bank to act as a regulator or a public backstop for the banking sector, and commercial banks were subject to frequent bouts of early withdrawals (Gorton and Tallman, 2016). Another potential application of this framework is emerging market economies in contemporary times.

\section{References}

Acharya, V. V., Schnabl, P., and Suarez, G. (2013). Securitization without risk transfer. Journal of Financial Economics, 107(3):515-536.

Adrian, T. and Ashcraft, A. B. (2012). Shadow Banking: A Review of the Literature. The New Palgrave Dictionary of Economics. Palgrave Macmillan.

Allen, F. and Gale, D. (1994). Limited market participation and volatility of asset prices. The American Economic Review, 84(4):933-955.

Allen, F. and Gale, D. (2005). From cash-in-the-market pricing to financial fragility. Journal of the European Economic Association, 3(2-3):535-546.

Ari, A. (2017). Sovereign risk and bank risk-taking. Mimeo, University of Cambridge.

Brunnermeier, M. K. (2009). Deciphering the liquidity and credit crunch 2007-2008. The Journal of economic perspectives, 23(1):77-100.

Claessens, S., Zoltan, P., Ratnovski, L., and Singh, M. (2012). Shadow banking: Economics and policy. Staff discussion note, IMF.

Covitz, D., Liang, N., and Suarez, G. (2013). The evolution of a financial crisis: Collapse of the asset-backed commercial paper market. Journal of Finance, 68(3):815-848. 
Diamond, D. W. and Dybvig, P. (1983). Bank runs, deposit insurance, and liquidity. Journal of Political Economy, 91(3):401-419.

Diamond, D. W. and Rajan, R. G. (2005). Liquidity shortages and banking crises. The Journal of Finance, 60(2):615-647.

Diamond, D. W. and Rajan, R. G. (2011). Fear of fire sales, illiquidity seeking, and credit freezes. The Quarterly Journal of Economics, 126(2):557-591.

Financial Stability Board (2017). Global Shadow Banking Monitoring Report 2016.

Gennaioli, N., Shleifer, A., and Vishny, R. W. (2013). A model of shadow banking. Journal of Finance, 68(4):1331-1363.

Goldstein, I. and Pauzner, A. (2005). Demand-deposit contracts and the probability of bank runs. Journal of Finance, 60(3):1293-1327.

Gornicka, L. A. (2016). Banks and shadow banks: Competitors or complements? Journal of Financial Intermediation, 27:118 - 131.

Gorton, G. and Metrick, A. (2012). Securitized banking and the run on repo. Journal of Financial Economics, 104(3):425-451.

Gorton, G. and Tallman, E. W. (2016). How Did Pre-Fed Banking Panics End? NBER Working Papers 22036, National Bureau of Economic Research, Inc.

Hanson, S. G., Shleifer, A., Stein, J. C., and Vishny, R. W. (2015). Banks as patient fixed income investors. Journal of Financial Economics, 117(3):449-469.

Harris, M., Opp, C. C., and Opp, M. M. (2014). Higher capital requirements, safer banks? macroprudential regulation in a competitive financial system. mimeo, University of Chicago, University of California, Berkeley and University of Pennsylvania.

Krishnamurthy, A. (2010). How debt markets have malfunctioned in the crisis. Journal of Economic Perspectives, 24(1):3-28.

Krishnamurty, A., Nagel, S., and Orlov, D. (2014). Sizing up repo. The Journal of Finance, $69(6): 2381-2417$.

Luck, S. and Schempp, P. (2016). Regulatory arbitrage and systemic liquidity crises. mimeo, Board of Governors of the Federal Reserve System and Max Planck Institute for Research on Collective Goods. 
Merrill, C. B., Nadauld, T. D., Stulz, R. M., and Sherlund, S. (2012). Did Capital Requirements and Fair Value Accounting Spark Fire Sales in Distressed Mortgage-Backed Securities? NBER Working Papers 18270, National Bureau of Economic Research, Inc.

Mitchell, M. and Pulvino, T. (2012). Arbitrage crashes and the speed of capital. Journal of Financial Economics, 104(3):469 - 490.

Moody's Investors Service (2007). Moody's ultimate recovery database. Special Comment.

Moreira, A. and Savov, A. (2017). The macroeconomics of shadow banking. The Journal of Finance.

Ordoñez, G. (2017). Sustainable shadow banking. American Economic Journal: Macroeconomics. Forthcoming.

Plantin, G. (2015). Shadow banking and bank capital regulation. Review of Financial Studies, 28(1):146-175.

Pozsar, Z., Adrian, T., Ashcraft, A. B., and Boesky, H. (2013). Shadow banking. Economic Policy Review, 19(Dec):1-16.

Shleifer, A. and Vishny, R. (2011). Fire Sales in Finance and Macroeconomics. Journal of Economic Perspectives, 25(1):29-48.

Stein, J. C. (2012). Monetary policy as financial stability regulation. The Quarterly Journal of Economics, 127(1):57.

\section{Appendix}

\section{A Proof of Proposition 1}

First, we take the early withdrawal of shadow bank deposits as given and derive the nowithdrawal condition. Expected consumption is given by

$$
(1-P) c_{b h}+p c_{b l}=M_{1}+\theta^{S B} d^{S B}+(1-p(1-\bar{V})) d^{T B} R^{T B}
$$

when households do not withdraw their deposits early from traditional banks, and

$$
c_{b}^{w}=M_{1}+\theta^{S B} d^{S B}+d^{T B}
$$


when they do. ${ }^{39}$ It is optimal for households not to withdraw their deposits when

$$
\begin{gathered}
(1-p) c_{b h}+p c_{b l} \geq c_{b}^{w} \\
\therefore V \geq \bar{V} \equiv \frac{1}{p}\left(\frac{1}{R^{T B}}-(1-p)\right)
\end{gathered}
$$

Jointly solving this with (13) yields $\bar{V}=1, R^{T B}=1$.

Next, we confirm that the early withdrawal from shadow banks is optimal. As shadow banks do not pay the commitment cost, they cannot commit to satisfying a no-withdrawal constraint. In equilibrium, it is optimal for households to withdraw their deposits early from shadow banks when

$$
(1-p) R^{S B}+p V^{S B} R^{S B}<1
$$

where $V^{S B}$ is defined according to (20). Using (14), (35) and (36), we can write

$$
\begin{aligned}
V^{S B} & =(1+\mu) \frac{\sigma_{l}}{\sigma_{h}} \\
R^{S B} & =\frac{\sigma_{h}}{(1-q) \sigma_{h}+q(1+\mu) P_{2}}
\end{aligned}
$$

and the condition becomes

$$
\frac{(1-p) \sigma_{h}+p(1+\mu) \sigma_{l}}{(1-q) \sigma_{h}+q(1+\mu) P_{2}}<1
$$

Consider the condition when $p=q$. It will then be satisfied for any $P_{2}>\sigma_{l}$ which must be true under (6). The necessary restriction on $p$ depends on the mark-up $\mu$. Specifically, when $\sigma_{h}<(1+\mu) \sigma_{l}$ we will need the restriction $p \geq q$ and vice versa with $\sigma_{h}<(1+\mu) \sigma_{l}$.

\section{B Limited liability}

Let $b l$ refer to the state with low asset payoffs. When the no-withdrawal constraint binds, the minimum recovery rate is limited to $\bar{V} \leq 1$ so that limited liability must also bind in $b l$. Therefore, we consider a scenario where both the no-withdrawal constraint and limited liability are slack. Since banks are always solvent, they borrow at the risk-free rate $R=1$ and profits in $b l$ are given by

$$
\Pi_{b l}=\sigma_{l} I_{2}+M_{2}-D
$$

and the bank's problem to maximize expected profits

$$
\max _{I_{1}, I_{2}, M_{1}, M_{2}}(1-q)\left[\sigma_{h} I_{1}+M_{1}\right]+q\left(\left[(1-p) \sigma_{h}+p \sigma_{l}\right] I_{2}+M_{2}\right)-D
$$

\footnotetext{
${ }^{39}$ Since households are atomistic, they do not internalize that their decision to withdraw deposits reduces the liquidation value of traditional banks.
} 
subject to (17), (19). Since $P_{2} \leq(1-p) \sigma_{h}+p \sigma_{l}$ given $\phi \leq 1$, assets are priced at or below their expected payoff after bad news. Therefore banks weakly prefer investing in $I_{2}$ over $M_{2}$ such that we can set

$$
\begin{aligned}
I_{2} & =I_{1}+\frac{M_{1}}{P_{2}} \\
M_{2} & =0
\end{aligned}
$$

This reduces the bank's problem to

$$
\max _{I_{1}, M_{1}} I_{1}+\left(1-q+\frac{q}{\phi}\right) M_{1}-\left(P_{1} I_{1}+M_{1}\right)
$$

and the first order conditions for $\left(I_{1}, M_{1}\right)$ are respectively

$$
\begin{gathered}
I_{1}: P_{1}=\frac{1}{(1+\mu)} \\
M_{1}: \phi=1
\end{gathered}
$$

where the inequality in (34) due to the possibility of a binding no-short-sale constraint. The bank's payoff in $b l$ can then be written as

$$
\Pi_{b l}=\left(\sigma_{l}-\frac{1}{1+\mu}\right) I_{1}+\left(\frac{\sigma_{l}}{(1-p) \sigma_{h}+p \sigma_{l}}-1\right) M_{1}
$$

and limited liability binds under the conditions

$$
\begin{gathered}
\sigma_{l}-\frac{1}{1+\mu}<0 \\
\frac{\sigma_{l}}{(1-p) \sigma_{h}+p \sigma_{l}}-1<0
\end{gathered}
$$

which are satisfied under (4). Therefore, we prove by contradiction that it is not possible for limited liability to be slack when assets yield a low payoff.

\section{Proof of Lemma 1}

The first order conditions to this problem indicate that shadow banks do not find it optimal to hold any cash $\left(M_{1}^{S B}=0\right)$ when $R^{S B}>1 .{ }^{40}$ Therefore, their liquidation value can be written as

$$
\theta^{S B}=\frac{P_{2}}{P_{1}^{S B}}
$$

\footnotetext{
${ }^{40}$ There is a no-short-sale constraint $\left(I_{1}, M_{1}\right) \geqq 0$ which is only binding for cash.
} 
where $P_{1}^{S B}$ is pinned down by the first order condition for the risky asset

$$
P_{1}^{S B}=\frac{\sigma_{h}}{1+\mu} \frac{1}{R^{S B}}
$$

Combining (36) and (14) yields

$$
P_{1}^{S B}=(1-q) \frac{\sigma_{h}}{1+\mu}+q P_{2}
$$

and by substituting this into (35) we attain

$$
\theta^{S B}=\frac{(1+\mu) P_{2}}{(1-q) \sigma_{h}+q(1+\mu) P_{2}}
$$

There will be a liquidity shortfall when $\theta^{S B}<1$. Since $\theta^{S B}$ is increasing in $P_{2}=\phi\left[(1-p) \sigma_{h}+p \sigma_{l}\right]$, setting $\phi=1$ provides a sufficient condition for this. With some algebra, we can write this condition as

$$
(1+\mu)\left[(1-p) \sigma_{h}+p \sigma_{l}\right]<\sigma_{h}
$$

A further sufficient condition can be attained by setting the mark-up to its maximum value $\mu=\bar{\mu}$. The condition then becomes $\sigma_{h}>1$ which must be true.

To get an expression for interest rates, we combine (38) with (14) such that

$$
R^{S B}=\frac{1}{1-q+q \frac{P_{2}}{\sigma_{h}}(1+\mu)}
$$

and $R^{S B}>1$ follows from $\theta^{S B}<1$.

Finally, substituting (17) and (36) into (23) gives an expression for the expected payoff

$$
E\left[\Pi^{S B}\right]=(1-q) \frac{\mu}{1+\mu} \sigma_{h} I_{1}^{S B}
$$

where $I_{1}^{S B}$ is attained by combining (37) with the asset supply schedule (3) such that

$$
I_{1}^{S B}=\left(A \alpha^{\alpha}\right)^{\frac{1}{1-\alpha}}\left((1-q) \frac{\sigma_{h}}{1+\mu}+q P_{2}\right)^{\frac{\alpha}{1-\alpha}}
$$

Observe that $I_{1}^{S B}, P_{1}^{S B}$ and $E\left[\Pi^{S B}\right]$ are all positive related to $P_{2}$. 


\section{Proof of Lemma 2}

After substituting for $\left(R^{T B}, \bar{V}\right)$ as per (16) and dropping the label ' $T B$ ' to simplify the exposition, the traditional bank's problem can be written in as

$$
\begin{gathered}
\Pi=(1-q)\left(\sigma_{h} I_{1}+M_{1}\right)+q(1-p)\left(\sigma_{h} I_{2}+M_{2}\right)-(1-q p) D \\
\text { s.t. } \\
P_{1} I_{1}+M_{1}=D \\
P_{2} I_{2}+M_{2}=P_{2} I_{1}+M_{1} \\
\sigma_{l} I_{2}+M_{2} \geq D \\
\left(I_{1}, I_{2}, M_{1}, M_{2}\right) \geqq 0
\end{gathered}
$$

where the last line represents no-short-sale constraints. There are three alternative cases depending on whether the no-withdrawal and no-short-sale constraint on $I_{2}$ bind. We first describe the case in Lemma 2, and then consider the remaining cases and prove that they may not be valid under the restrictions $\mu \leq \bar{\mu}, \phi>\underline{\phi}$

\section{D.1 Case 1}

Lemma 2 describes the case where the no-withdrawal constraint (41) and the no-short-sale constraint on $I_{2}$ bind. With $I_{2}=0$, the second period budget constraint (40) and the nowithdrawal constraint can respectively be written as

$$
\begin{aligned}
& M_{2}=P_{2} I_{1}+M_{1} \\
& M_{2}=P_{1} I_{1}+M_{1}
\end{aligned}
$$

Therefore, the no-withdrawal constraint may only be satisfied with $I_{1}>0$ when

$$
P_{1}=P_{2}
$$

which pins down $P_{1}$ and also corresponds to

$$
I_{1}=\left(A \alpha^{\alpha}\right)^{\frac{1}{1-\alpha}} P_{2}^{\frac{\alpha}{1-\alpha}}
$$

as per $(3) \cdot{ }^{41}$

Note also that the no-withdrawal constraint prevents the bank from converting $M_{1}$ to risky assets in the second period as long as $\phi>\underline{\phi}$. As such, the bank may not profit from holding

\footnotetext{
${ }^{41}$ Any solution with $I_{1}=0$ is sub-optimal as $(3)$ indicates that $P_{1}$ would approach zero.
} 
cash in the first period and $M_{1}$ is indeterminate. Therefore, the expected payoff can be written as

$$
\begin{aligned}
E\left[\Pi^{T B}\right] & =(1-q)\left(\sigma_{h}-P_{2}\right) I_{1} \\
& =(1-q)\left(\sigma_{h}-P_{2}\right)\left(A \alpha^{\alpha}\right)^{\frac{1}{1-\alpha}} P_{2}^{\frac{\alpha}{1-\alpha}}
\end{aligned}
$$

and its derivative with respect to $P_{2}$ is

$$
\frac{\partial E\left[\Pi^{T B}\right]}{\partial P_{2}}=\left(A \alpha^{\alpha}\right)^{\frac{1}{1-\alpha}} \frac{1-q}{1-\alpha}\left(\frac{\alpha \sigma_{h}}{P_{2}}-1\right) P_{2}^{\frac{\alpha}{1-\alpha}}
$$

such that

$$
\frac{\partial E\left[\Pi^{T B}\right]}{\partial P_{2}}<0 \forall P_{2}>\alpha \sigma_{h}
$$

\section{D.2 Case 2}

In the second case, the no-withdrawal constraint binds but the no-short-sale constraint is slack. By combining (40) and (41), we can write

$$
\begin{aligned}
I_{2} & =\frac{P_{2}-P_{1}}{P_{2}-\sigma_{l}} I_{1} \\
M_{2} & =P_{2}\left(\frac{P_{1}-\sigma_{l}}{P_{2}-\sigma_{l}}\right) I_{1}+M_{1}
\end{aligned}
$$

where $P_{2}>\sigma_{l}$ follows from $\phi>\underline{\phi}$ and $M_{1}$ is indeterminate as in Case 1. Substituting these into (39) yields the following first order condition for $I_{1}$

$$
P_{1}=\frac{1}{1+\mu} \frac{(1-q) \sigma_{h}\left(P_{2}-\sigma_{l}\right)+q(1-p)\left(\sigma_{h}-\sigma_{l}\right) P_{2}}{q(1-p)\left(\sigma_{h}-P_{2}\right)+(1-q p)\left(P_{2}-\sigma_{l}\right)}
$$

and the expected payoff is

$$
\Pi=\left[(1-q) \sigma_{h}+q(1-p)\left(\sigma_{h}-\sigma_{l}\right) \frac{P_{2}}{P_{2}-\sigma_{l}}\right] \frac{\mu}{1+\mu} I_{1}
$$

Finally, we derive a condition to eliminate this case by considering the no-short-sale constraint $I_{2} \geq 0$. Since $P_{2}>\sigma_{l}, I_{1}>0,(42)$ indicates that $I_{2} \geq 0$ will bind when

$$
P_{2}<P_{1}
$$


Using (43), we can write this as

$$
P_{2}<\frac{1}{1+\mu} \frac{(1-q) \sigma_{h}\left(P_{2}-\sigma_{l}\right)+q(1-p)\left(\sigma_{h}-\sigma_{l}\right) P_{2}}{(1-q p)\left(P_{2}-\sigma_{l}\right)+q(1-p)\left(\sigma_{h}-P_{2}\right)}
$$

which implicitly establishes a boundary fire-sale discount $\hat{\phi}$ above which the no-short-sale constraint is slack. ${ }^{42}$ Case 2 is eliminated for all $\phi \in[0,1]$ when $\hat{\phi}>1$. The relevant condition can then be attained by combining (45) with $\phi=1$ such that

$$
\begin{gathered}
(1-p) \sigma_{h}+p \sigma_{l}<\frac{1}{1+\mu} \\
\therefore \mu<\bar{\mu}
\end{gathered}
$$

which indicates that the mark-up restriction (4) eliminates Case 2.

Note also that even in the absence of the restriction (4), the equilibrium fire-sale never occurs under this case since the expected payoff (44) is decreasing in $\phi$. Without the restriction (4), the size of the shadow banking sector simply continues to expand until $\phi<\hat{\phi}$ and the equilibrium occurs under Case 1.

$$
\bar{\phi} \equiv \frac{(1-q) \frac{\sigma_{h}}{1+\mu}+q \sigma_{l}}{(1-p) \sigma_{h}+p \sigma_{l}}
$$

\section{D.3 Case 3}

In the third case, the no-withdrawal constraint is slack. Due to limited liability, banks strictly prefer to convert their cash to risky assets $I_{2}$ following bad news to profit from the decline in $P_{2}$. Therefore, we can write

$$
\begin{aligned}
I_{2} & =I_{1}+\frac{M_{1}}{P_{2}} \\
M_{2} & =0
\end{aligned}
$$

and the first order conditions for $\left(M_{1}, P_{1}\right)$ are respectively written as

$$
\begin{aligned}
& P_{1}=\frac{\sigma_{h}}{1+\mu} \\
& P_{2}<\sigma_{h}
\end{aligned}
$$

Since $P_{2}<\sigma_{h}$ even without a fire-sale under bad news, banks optimally hold $M_{1} \rightarrow \infty$.

\footnotetext{
${ }^{42}$ With $\sigma_{l}=0$, we can get an explicit expression $\hat{\phi}=\frac{1}{1-q}\left(\frac{1}{1+\mu} \frac{1-q p}{1-p}-q\right)$.
} 
In other words, with the no-withdrawal constrain slack, banks find it profitable to hold as much cash as possible in the first period and then convert all of it into risky assets after bad news. Since each unit of $M_{1}$ requires a unit of deposits, and risky assets contribute to low state revenues by $\sigma_{l}<1$, it is impossible for the no-withdrawal constraint to remain slack under this investment strategy. Therefore, Case 3 is also eliminated.

\section{E Solution under $\phi=\underline{\phi}$}

Suppose $\phi<\underline{\phi}$ and hence $P_{2}<\sigma_{l}$ such that traditional banks benefit from buying risky assets both in terms of profits and in terms of the no-withdrawal constraint. Therefore, they find it optimal to hold risky assets until the secondary market price returns to $P_{2}=\sigma_{l}$ (i.e. $\phi=\underline{\phi}$ ). Let $\tilde{I}_{2}$ indicate the level of assets that achieve this, implicitly defined by the expression ${ }^{43}$

$$
\frac{\sigma_{l}}{(1-p) \sigma_{h}+p \sigma_{l}}=f\left(\gamma I_{1}^{S B}+(1-\gamma)\left(I_{1}-\tilde{I}_{2}\right)\right)
$$

Once the secondary market price reaches $P_{2}=\sigma_{l}$, the no-withdrawal constraint binds and traditional banks behave as described in 2. Therefore, $I_{1}$ is set according to $P_{1}=P_{2}=\sigma_{l}$ and traditional banks' holdings of safe assets in period 2 is given by

$$
\begin{aligned}
M_{2} & =P_{2} I_{1}-P_{2} \tilde{I}_{2} \\
& =\sigma_{l}\left(I_{1}-\tilde{I}_{2}\right)
\end{aligned}
$$

where we have taken advantage of the indeterminacy of $M_{1} \geq 0$ to set $M_{1}=0$. Finally, expected profits are given by

$$
\begin{aligned}
E[\Pi] & =\left(\sigma_{h}-\sigma_{l}\right)\left[(1-q) I_{1}+q(1-p) \tilde{I}_{2}\right] \\
& =\left(\sigma_{h}-\sigma_{l}\right)\left[(1-q) A^{\frac{1}{1-\alpha}}\left(\alpha \sigma_{l}\right)^{\frac{\alpha}{1-\alpha}}+q(1-p) \tilde{I}_{2}\right]
\end{aligned}
$$

So far, we have assumed that traditional banks remain net-sellers with $\tilde{I}_{2} \leq I_{1}$. When the excess supply of assets is particularly large, we may have $P_{2}<\sigma_{l}$ even when traditional banks hold on to their risky assets such that $\tilde{I}_{2}=I_{1}$. In this case, they will find it optimal to increase $D$ and $M_{1}$ use this to purchase risky assets in period 2 until $P_{2}=\sigma_{l}$. As before, the

\footnotetext{
${ }^{43}$ We drop the label ' $T B$ ' to simplify the exposition
} 
no-withdrawal constraint will bind at $P_{2}=\sigma_{l}$ and the complete solution is

$$
\begin{aligned}
P_{1} & =P_{2} \\
I_{2} & =I_{1}+\frac{1}{\sigma_{l}} \tilde{M}_{1} \\
M_{2} & =0 \\
D & =P_{1} I_{1}+\tilde{M}_{1}=\sigma_{l} I_{1}+\tilde{M}_{1}
\end{aligned}
$$

where $\tilde{M}_{1}$ takes on the role of ensuring $P_{2}=\sigma_{l}$ and is implicitly defined by

$$
\frac{\sigma_{l}}{(1-p) \sigma_{h}+p \sigma_{l}}=f\left(\gamma I_{1}^{S B}-(1-\gamma) \frac{1}{\sigma_{l}} \tilde{M}_{1}\right)
$$

and the expected payoff is

$$
\begin{aligned}
E[\Pi] & =\left(\sigma_{h}-\sigma_{l}\right)\left((1-q p) A^{\frac{1}{1-\alpha}}\left(\alpha \sigma_{l}\right)^{\frac{\alpha}{1-\alpha}}+q(1-p) \frac{1}{\sigma_{l}} \tilde{M}_{1}\right) \\
& =\left(\sigma_{h}-1\right)\left(\frac{1-q p}{q p} A^{\frac{1}{1-\alpha}}\left(\alpha \frac{1-(1-q p) \sigma_{h}}{q p}\right)^{\frac{\alpha}{1-\alpha}}+\frac{q(1-p)}{1-(1-q p) \sigma_{h}} \tilde{M}_{1}\right)
\end{aligned}
$$

There are two notable implications. First, the secondary market price cannot go below $\sigma_{l}$. Second, a rise in the shadow banking sector size $\gamma$ first leads to a rise in $\tilde{I}_{2}$, and then $\tilde{M}_{1}$. The above solution shows that $\tilde{M}_{1}$ and $E[\Pi]$ rises in this case while everything else stays constant. As we move to a limiting case with only shadow banks, safe asset holdings and traditional bank profits both approach infinity

$$
\lim _{\gamma \rightarrow 1} E\left[\Pi^{T B}\right]=\lim _{\gamma \rightarrow 1} \tilde{M}_{1}=\infty
$$

which guarantees an inferior equilibrium for a sufficiently high commitment cost $\tau>\bar{\tau}$.

\section{F Proof for Proposition 2}

For the purposes of the proof, it is convenient to introduce some additional notation. Let $\phi^{*}$ denote the equilibrium fire-sale discount and the functions $\left(\pi^{S B}(),. \pi^{T B}().\right)$ map from the fire-sale discount to expected payoffs from shadow and traditional banking such that

$$
\begin{aligned}
& \pi^{S B}(\phi)=(1-q) \frac{\mu}{1+\mu} \sigma_{h}\left(A \alpha^{\alpha}\right)^{\frac{1}{1-\alpha}}\left((1-q) \frac{\sigma_{h}}{1+\mu}+q \phi\left[(1-p) \sigma_{h}+p \sigma_{l}\right]\right)^{\frac{\alpha}{1-\alpha}} \\
& \pi^{T B}(\phi)=(1-q)\left(\sigma_{h}-\phi\left[(1-p) \sigma_{h}+p \sigma_{l}\right]\right)\left(A \alpha^{\alpha}\right)^{\frac{1}{1-\alpha}}\left(\phi\left[(1-p) \sigma_{h}+p \sigma_{l}\right]\right)^{\frac{\alpha}{1-\alpha}}
\end{aligned}
$$


as per Lemma 1 and Lemma 2. There is an interior equilibrium when the following sufficient conditions are satisfied

$$
\begin{aligned}
\pi^{S B}(\bar{\phi}) & >\pi^{T B}(\bar{\phi})-\tau \\
\pi^{S B}(\underline{\phi}) & >\pi^{T B}(\underline{\phi})-\tau \\
\frac{\partial \pi^{S B}(\phi)}{\partial \phi} & >\frac{\partial \pi^{T B}(\phi)}{\partial \phi} \forall \phi \in\left(\phi^{*}, 1\right) \\
\frac{\partial \phi}{\partial \gamma} & <0 \forall \gamma \in[0,1]
\end{aligned}
$$

where $\tau>0$. In the sections below, we show that these conditions will be satisfied within a range of commitment costs $\tau \in(\underline{\tau}, \bar{\tau})$ and also show that this range is non-empty.

\section{F.1 Proof for condition (46)}

The condition depends on the effective value taken by

$$
\bar{\phi} \equiv \min \left[1, \frac{(1-q) \frac{\sigma_{h}}{1+\mu}+q \sigma_{l}}{(1-p) \sigma_{h}+p \sigma_{l}}\right]
$$

When we have

$$
\mu<\frac{(p-q)\left(\sigma_{h}-1\right)}{q p(1-q) \sigma_{h}-(p-q)\left(\sigma_{h}-1\right)}
$$

such that $\bar{\phi}=1$, the relevant condition is

$$
\pi^{S B}(1)>\pi^{T B}(1)-\tau
$$

Using the definitions for $\left(\pi^{S B}(),. \pi^{T B}().\right)$, we can write this condition as a minimum commitment cost

$$
\begin{aligned}
\tau & \geq \underline{\tau} \equiv(1-q)\left(A \alpha^{\alpha}\right)^{\frac{1}{1-\alpha}}\left(\sigma_{h}-1\right)\left(\frac{1}{q}\right)^{\frac{1}{1-\alpha}}\left(1-(1-q) \sigma_{h}\right)^{\frac{\alpha}{1-\alpha}} \\
& -(1-q)\left(A \alpha^{\alpha}\right)^{\frac{1}{1-\alpha}} \frac{\mu}{1+\mu} \sigma_{h}\left(1-\frac{\mu}{1+\mu}(1-q) \sigma_{h}\right)^{\frac{\alpha}{1-\alpha}}>0
\end{aligned}
$$

As an aside, we also show that $\underline{\tau}>0$ such that a commitment cost is necessary for an interior equilibrium. To do this, note that the expected payoff under Case 1 and Case 2 of the traditional bank's problem in Appendix D are equivalent when $\phi=1, \mu=\bar{\mu}$. For any $\mu<\bar{\mu}$, profits under Case 1 are higher. Therefore, we can write a sufficient condition 


$$
\begin{gathered}
\left(A \alpha^{\alpha}\right)^{\frac{1}{1-\alpha}} \frac{\bar{\mu}}{1+\bar{\mu}}\left(\frac{1}{1+\bar{\mu}}\right)^{\frac{\alpha}{1-\alpha}}>\left(A \alpha^{\alpha}\right)^{\frac{1}{1-\alpha}} \frac{\bar{\mu}}{1+\bar{\mu}}(1-q) \sigma_{h}\left(1-\frac{\bar{\mu}}{1+\bar{\mu}}(1-q) \sigma_{h}\right)^{\frac{\alpha}{1-\alpha}} \\
\therefore 1>(1-q) \sigma_{h}\left(1+\bar{\mu}\left(1-(1-q) \sigma_{h}\right)\right)^{\frac{\alpha}{1-\alpha}}
\end{gathered}
$$

Since $\frac{\alpha}{1-\alpha}<1$ for $\alpha<\frac{1}{2}$, we can eliminate the power and substitute for $\bar{\mu}=\frac{(1-q)\left(\sigma_{h}-1\right)}{1-(1-q) \sigma_{h}}$ to get a sufficient condition

$$
(1-q) \sigma_{h}\left[(1-q) \sigma_{h}+q\right]<1
$$

Note that the RHS is increasing in $\sigma_{h}$. A further sufficient condition is then to set $\sigma_{l}=0$ which maximizes $\sigma_{h}$. We can then see that the above condition is true for all $p<1$. Therefore, we can show that $\tau>0$ under the two conditions

$$
\begin{aligned}
& \alpha<\frac{1}{2} \\
& \mu \leq \bar{\mu}
\end{aligned}
$$

When (50) is not satisfied such that $\bar{\phi}<1$, the relevant condition for (46) is

$$
\pi^{S B}(\bar{\phi})>\pi^{T B}(\bar{\phi})-\tau
$$

which leads to a higher minimum commitment cost

$$
\begin{aligned}
\underline{\tau}= & (1-q)\left(A \alpha^{\alpha}\right)^{\frac{1}{1-\alpha}}\left(\sigma_{h}-\bar{\phi}\left[(1-p) \sigma_{h}+p \sigma_{l}\right]\right)\left(\bar{\phi}\left[(1-p) \sigma_{h}+p \sigma_{l}\right]\right)^{\frac{\alpha}{1-\alpha}}- \\
& (1-q)\left(A \alpha^{\alpha}\right)^{\frac{1}{1-\alpha}} \frac{\mu}{1+\mu} \sigma_{h}\left((1-q) \frac{\sigma_{h}}{1+\mu}+q \bar{\phi}\left[(1-p) \sigma_{h}+p \sigma_{l}\right]\right)^{\frac{\alpha}{1-\alpha}}
\end{aligned}
$$

where the aside on $\tau>0$ is still valid.

\section{F.2 Proof for condition (47)}

It follows from Appendix E that (47) will be satisfied when the lower bound restriction on $\phi$ is violated such that

$$
\underline{\phi}>f\left(\left(A \alpha^{\alpha}\right)^{\frac{1}{1-\alpha}}\left((1-q) \frac{\sigma_{h}}{1+\mu}+q \sigma_{l}\right)^{\frac{\alpha}{1-\alpha}}\right)
$$

for any $\tau<\infty$. Therefore, we do not necessarily need an upper bound on the commitment cost for an interior equilibrium. However, the interior equilibrium has different properties in the region $\phi<\underline{\phi}$ (as described in Appendix E) and we impose an upper bound on the commitment cost to prevent this.

Let $\widetilde{\phi} \equiv \frac{\alpha \sigma_{h}}{(1-p) \sigma_{h}+p \sigma_{l}}$ denote the fire-sale discount that maximizes traditional bank profits. 
The upper bound depends on where $\widetilde{\phi}$ stands relative to $\underline{\phi}$. When the following condition is true

$$
\sigma_{h} \geq \frac{1}{1-q p(1-\alpha)}
$$

such that $\widetilde{\phi}>\underline{\phi}$, the upper bound for commitment costs $\bar{\tau}$ must satisfy

$$
\pi^{S B}(\widetilde{\phi})<\pi^{T B}(\widetilde{\phi})-\tau
$$

which yields the upper bound

$$
\tau \leq \bar{\tau}=(1-q)\left(\sigma_{h} A \alpha^{\alpha}\right)^{\frac{1}{1-\alpha}}\left[(1-\alpha) \alpha^{\frac{\alpha}{1-\alpha}}-\frac{\mu}{1+\mu}\left(\frac{1-q}{1+\mu}+q \alpha\right)^{\frac{\alpha}{1-\alpha}}\right]
$$

When (51) is not satisfied, the fire-sale discount hits $\phi=\underline{\phi}$ before traditional bank profits peak and the upper bound is given by

$$
\tau \leq \bar{\tau}=(1-q)\left(A \alpha^{\alpha}\right)^{\frac{1}{1-\alpha}}\left[\left(\sigma_{h}-\sigma_{l}\right) \sigma_{l}^{\frac{\alpha}{1-\alpha}}-\frac{\mu}{1+\mu} \sigma_{h}\left((1-q) \frac{\sigma_{h}}{1+\mu}+q \sigma_{l}\right)^{\frac{\alpha}{1-\alpha}}\right]
$$

Note that, regardless of the value taken by $(\bar{\tau}, \underline{\tau})$, it follows from $(48)$ that $\bar{\tau}>\underline{\tau}$.

\section{F.3 Proof for condition (48)}

This follows directly from Lemma 1, which shows that

$$
\frac{\partial \pi^{S B}(\phi)}{\partial \phi}>0 \forall \phi \in(0,1)
$$

and Lemma 2 which shows that

$$
\frac{\partial \pi^{T B}(\phi)}{\partial \phi}<0 \forall \phi \in(\widetilde{\phi}, \bar{\phi})
$$

where $\phi^{*}>\widetilde{\phi}$ since the latter is the peak of traditional bank profits in the range above $\underline{\phi}$.

\section{F.4 Proof for condition (49)}

Recall that the excess supply of assets is given by

$$
\widetilde{I}=\gamma I_{1}^{S B}+(1-\gamma)\left(I_{1}^{T B}-I_{2}^{T B}\right)>0
$$


where $\left(I_{1}^{S B}, I_{1}^{T B}\right)$ depend on $\phi$ and $I_{2}^{T B}=0$. Given that $f($.$) is continuous and decreasing, to$ satisfy (49) we require that

$$
\frac{\partial \widetilde{I}}{\partial \gamma}=I_{1}^{S B}-I_{1}^{T B}>0 \forall \gamma \in[0,1]
$$

which is equivalent to

$$
I_{1}^{S B}>I_{1}^{T B} \forall \phi \in(\underline{\phi}, \bar{\phi}]
$$

At any given $\phi$, we have $I_{1}^{S B}>I_{1}^{T B}$ when the following condition is satisfied

$$
q \sigma_{h}>(1+\mu) \phi\left[1-(1-q) \sigma_{h}\right]
$$

Since the RHS is increasing in $\mu$ and $\phi$, a sufficient condition is to set $\phi=1, \mu=\bar{\mu}$, which will be satisfied for $\sigma_{h}>1$.

Since $\left(I_{1}^{S B}, I_{1}^{T B}\right)$ both decrease in $\phi$ at different rates, we also need to show that $I_{1}^{S B}$ at $\underline{\phi}$ is lower than $I_{1}^{T B}$ at $\bar{\phi}$. This will be true with $\bar{\phi}=1$ when (50) is satisfied. Otherwise, $\bar{\phi}$ will need to satisfy

$$
\bar{\phi}=\frac{(1-q) \frac{\sigma_{h}}{1+\mu}+q \sigma_{l}}{(1-p) \sigma_{h}+p \sigma_{l}}
$$

which is precisely how we define the upper bound restriction on the fire-sale discount.

\section{F.5 Proof for the non-emptiness of $(\underline{\tau}, \bar{\tau})$}

Finally, we prove that $\bar{\tau}>\underline{\tau}$ such that there is a non-empty set of commitment costs that bring about an interior equilibrium. Since there are two alternatives values for both $\bar{\tau}$ and $\underline{\tau}$, we consider each in turn. First suppose that (50) is satisfied so that $\underline{\tau}$ is in line with $\phi=1$. Then it follows from Lemma 2 that $\bar{\tau}>\underline{\tau}$ regardless of which value $\bar{\tau}$ takes. Second, suppose (50) is not satisfied so that $\underline{\tau}$ is in line with $\bar{\phi}<1$. When (51) is also not satisfied such that traditional bank profits do not peak until $\underline{\phi}, \bar{\tau}>\underline{\tau}$ follows from $\bar{\phi}>\underline{\phi}$.

The only case where we need impose an additional condition corresponds to (51) being satisfied so that $\bar{\tau}$ is in line with the peak $\phi=\frac{\alpha \sigma_{h}}{(1-p) \sigma_{h}+p \sigma_{l}}$ while (50) is not satisfied such that $\bar{\phi}<1$. The condition for non-emptiness is then equivalent to

$$
\begin{aligned}
\tilde{\phi} & <\bar{\phi} \\
\therefore \frac{\alpha \sigma_{h}}{(1-p) \sigma_{h}+p \sigma_{l}} & <\frac{(1-q) \frac{\sigma_{h}}{1+\mu}+q \sigma_{l}}{(1-p) \sigma_{h}+p \sigma_{l}}
\end{aligned}
$$

A sufficient condition is

$$
\alpha<1-p
$$


which should be satisfied when $\alpha<0.5, p \leq 0.5$.

\section{G $\quad$ Proof for Proposition 3}

We first solve the household's problem to attain the expressions (28), (29). Allowing for liquidity risk, the household's problem can be written as

$$
\begin{gathered}
\max _{d^{S B}, d^{T B}, M_{1}, M_{2}}(1-q) C_{g h}+q(1-p) C_{b h}+q p C_{b l} \\
\text { s.t. } \\
d^{S B}+d^{T B}+M_{1}=E \\
M_{2}=M_{1}+\theta^{S B} d^{S B} \\
C_{g h}=M_{1}+d^{T B} R^{T B}+d^{S B} R^{S B} \\
C_{b h}=M_{2}+\left[(1-\xi) R^{T B}+\xi \theta^{T B}\right] d^{T B} \\
C_{b l}=M_{2}+\left[(1-\xi) \bar{V} R^{T B}+\xi \theta^{T B}\right] d^{T B}
\end{gathered}
$$

with the first order conditions (14) for deposits in shadow banks and

$$
R^{T B}=1+\frac{q \xi\left(1-\theta^{T B}\right)+q p(1-\xi)(1-\bar{V})}{1-q(\xi+(1-\xi) p(1-\bar{V}))}
$$

for deposits in traditional banks. ${ }^{44}$

\section{Early withdrawal decision and market discipline}

We assume that the bank-run and the early withdrawal decision take place simultaneously such that, realistically, households may not secure themselves from bank-runs with an early withdrawal. Expected consumption without and with an early withdrawal are then respectively given by

$$
\begin{aligned}
(1-P) c_{b h}+p c_{b l} & =M_{1}+\theta^{S B} d^{S B}+\left[(1-p(1-\bar{V}))(1-\xi) R^{T B}+\xi \theta^{T B}\right] d^{T B} \\
c_{b}^{w} & =M_{1}+\theta^{S B} D^{S B}+\left(1-\left(1-\theta^{T B}\right) \xi\right) D^{T B}
\end{aligned}
$$

where the latter expression indicates that a household that decides to withdraw its deposit early may receive an incomplete repayment due to a bank-run. Under this set up, all terms

\footnotetext{
${ }^{44}$ Under the sequential service constraint, a portion $\theta^{T B}$ of depositors are able to withdraw all of their funds during a bank-run while the remainder receive no payment. We assume that the outcome of an attempted withdrawal is idiosyncratic to the household-bank pairing and that households diversify their holdings across a large number of traditional banks. This does not affect our results but streamlines the exposition by preventing households from becoming heterogenous in whether they have been repaid.
} 
that relate to the bank-run probability cancel out and the minimum repayment rate schedule is given by

$$
\begin{gathered}
(1-P) c_{b h}+p c_{b d} \geq c_{b}^{w} \\
\therefore V \geq \bar{V} \equiv \frac{1}{p}\left(\frac{1}{R^{T B}}-(1-p)\right)
\end{gathered}
$$

which remains identical to the simple model. Combining (52) and (53) then yields

$$
\begin{aligned}
\bar{V} & =1-\frac{q}{p} \frac{\xi\left(1-\theta^{T B}\right)}{1-q\left(1-\xi\left(1-\theta^{T B}\right)\right)} \\
R^{T B} & =1+\frac{q}{1-q} \xi\left(1-\theta^{T B}\right)
\end{aligned}
$$

With $\xi=0$, these expressions simplify to $\bar{V}=R^{T B}=1$. Note that $\bar{V}$ is decreasing in $\xi$ and $R^{T B}$ is increasing. Therefore a rise in $\xi$ leads to

$$
\bar{V}<1<R^{T B}
$$

\section{Fire-sale on the safe asset and liquidity shortfall}

Finally, we show that the fire-sale on the safe is a crucial determinant of liquidity risk. Consider the liquidation value given by (31). There will be no liquidity shortfall such that $\theta^{T B}=1$ under the condition

$$
P_{2}(r) I_{2}^{T B}(r)+P_{2}(s) I_{2}^{T B}(s) \geq D^{T B}
$$

First, consider the case without a fire-sale on safe assets such that $P_{2}(s)=1$. The condition becomes

$$
I_{2}^{T B}(r)+I_{2}^{T B}(s) \geq D^{T B}
$$

and will be true under any investment strategy that satisfies the no-withdrawal constraint (30) as long as

$$
P_{2}(r) \geq \sigma_{l}
$$

To see that this must be true, consider what would happen otherwise. Since traditional banks are protected by limited liability, they do not internalize the state with weak fundamentals. Therefore, given $P_{2}(s)=1 \geq P_{2}(r)$, traditional banks always prefer to purchase risky assets which yield a higher return in the state where they remain solvent. Ordinarily, traditional banks' risky asset purchases are limited by the no-withdrawal constraint. However, with $P_{2}(r)<\sigma_{l}$ and $P_{2}(s)=1$, the strategy of selling a safe asset and purchasing risky assets with the funds increases the recovery rate $V$. Consequently, traditional banks increase their purchases of risky assets until their price rises to $P_{2}(r)=\sigma_{l}$.

58

(C)International Monetary Fund. Not for Redistribution 
Second, consider the case with a fire-sale on safe assets such that $P_{2}(s)=\phi$. Since shadow banks are liquidated after bad news, and traditional banks re-allocate their portfolio from risky to safe assets, there is an excess supply of risky assets at all times such that $P_{2}(r)=\phi$. We can then write the condition for $\theta^{T B}=1$ as

$$
\phi\left(I_{2}^{T B}(r)+I_{2}^{T B}(s)\right) \geq D^{T B}
$$

Note that the no-withdrawal constraint is not tightened by a decline in $\phi$ when both safe and risky assets are in excess supply, since the terms of trade between the two assets do not change, while the value of liquid asset holdings increase. Therefore, for sufficiently low $\phi,(54)$ fails and there is a liquidity shortfall $\theta^{T B}<1$.

\section{H Example fire-sale function}

To attain a simple fire-sale function from the outsider investor's problem, we can simply parameterize the payoff function from the outside investment to

$$
g(\widetilde{K})=\kappa^{-1} \ln (\widetilde{K})
$$

where $\kappa>0$. The fire-sale function then becomes

$$
f(\widetilde{I})=\frac{\kappa \widetilde{E}}{1+\kappa\left[(1-p) \sigma_{h}+p \sigma_{l}\right] \widetilde{I}}
$$

To satisfy the lower bound condition exactly, we need to set $\widetilde{E}$ at a level that yields $f\left(I_{1}^{S B}\right)=$ $\underline{\phi}$ at $\gamma=0$, which is

$$
\widetilde{E}=\underline{\phi}\left[\frac{1}{\kappa}+\left(A \alpha^{\alpha}\right)^{\frac{1}{1-\alpha}}\left((1-q) \frac{\sigma_{h}}{1+\mu}+\frac{1-(1-q p) \sigma_{h}}{p}\right)^{\frac{\alpha}{1-\alpha}}\right]
$$

and the upper bound will approach but never exceed $\bar{\phi}$ as $\kappa$ rises.

\section{Description of the model with liquidity risk}

We describe banks and entrepreneurs below. Outside investors are described in Section 4.2 while households are described under Appendix G. 


\section{I.1 Entrepreneurs}

Entrepreneurs only differ from those described in Section 3.1.1 in that they may produce all three asset types $i \in\{\lambda, s, r\}$. We assume that they have a Cobb-Douglas production function that is additively separable in the asset type such that

$$
I_{1}(i)=A K(i)^{\alpha} \forall i \in\{\lambda, s, r\}
$$

where $K(i)$ is an investment in capital specific to the asset type. This yields the set of first order conditions

$$
P_{1}(i)=\frac{1}{\alpha A^{\frac{1}{\alpha}}} I_{1}(i)^{\frac{1-\alpha}{\alpha}} \forall i \in\{\lambda, s, r\}
$$

where we impose a constant markup $\mu$ across assets for simplicity.

\section{I.2 Banks}

With a richer asset space, the first period budget constraint becomes

$$
\sum_{i \in\{\lambda, s, r\}} P_{1}(i) I_{1}(i)=D
$$

where $I_{1}(i)$ is the amount purchased of an asset $i$ and $P_{1}(i)$ is the corresponding asset price. As in the simple model, assets are priced at their expected payoff in the secondary market after good news and trade is inconsequential. Bank profits (in the third period) are then given by

$$
\Pi_{g h}=\sigma_{h} I_{1}(r)+I_{1}(s)+I_{1}(\lambda)-D R
$$

Following bad news, banks face the second period budget constraint

$$
\sum_{i \in\{s, r\}}\left(P_{2}(i)-P_{1}(i)\right) I_{1}(i)=I_{1}(\lambda)
$$

and have a liquidation value

$$
\theta=\min \left\{1, \frac{P_{2}(r) I_{2}(r)+P_{2}(s) I_{2}(s)}{D}\right\}
$$

When risky assets yield a high payoff $\sigma_{h}$ in the third period, banks make a profit

$$
\Pi_{g h}=\sigma_{h} I_{2}(r)+I_{2}(s)-D R
$$

while limited liability binds under a low asset payoff $\sigma_{l}$. Under limited liability, banks make 
zero profits and deposits pay a recovery rate

$$
V=\min \left\{1, \frac{\sigma_{l} I_{2}(r)+I_{2}(s)}{D R}\right\}
$$

which is proportional to the shortfall of funds. We can use this expression to write the nowithdrawal constraint for traditional banks as

$$
\sigma_{l} I_{2}^{T B}(r)+I_{2}^{T B}(s) \geq \bar{V} D^{T B} R^{T B}
$$

Next, we evaluate the optimal behaviour of banks under the two alternative strategies of shadow and traditional banking. The free entry condition is given by (26) as in the simple model.

\section{Shadow banking}

Shadow banks choose $\left\{I_{1}^{S B}(i), D^{S B}, i \in\{\lambda, s, r\}\right\}$ to maximize their expected profits

$$
E\left[\Pi^{S B}\right]=(1-q)\left(\sigma_{h} I_{1}^{S B}(r)+I_{1}^{S B}(s)+I_{1}^{S B}(\lambda)-D^{S B} R^{S B}\right)
$$

subject to (56). The optimal portfolio allocation is then determined by the set of first order conditions

$$
\begin{aligned}
& P_{1}(r)=\frac{\sigma_{h}}{(1+\mu) R^{S B}} \\
& P_{1}(s)=P_{1}(\lambda)=\frac{1}{(1+\mu) R^{S B}}
\end{aligned}
$$

which allow us to back out the asset holdings in period 1 using (55).

\section{Traditional banking}

Traditional banks choose $\left\{I_{1}^{T B}(i), I_{2}^{T B}(r), I_{2}^{T B}(s), M_{1}^{T B}, M_{2}^{T B}, D^{T B}, i \in\{\lambda, s, r\}\right\}$ to maximize their expected profits

$$
\begin{aligned}
E\left[\Pi^{T B}\right]= & (1-q)\left(\sigma_{h} I_{1}^{T B}(r)+I_{1}^{T B}(s)+I_{1}^{T B}(\lambda)\right) \\
& +q(1-p)(1-\xi)\left(\sigma_{h} I_{2}^{T B}(r)+I_{2}^{T B}(s)\right) \\
& -(1-q+q(1-p)(1-\xi)) D^{T B} R^{T B}
\end{aligned}
$$

subject to (56), (57) and (59). Due to their ability to commit, traditional banks also internalize the relationship between their liquidation value $\theta^{T B}$ given by (58) and the minimum recovery rate $\bar{V}$ and $R^{T B}$ as per the expressions in Proposition 3. 
We focus on the case with a slack no-short-sale constraint

$$
I_{1}^{T B}(r)>0
$$

which is the case presented in our results. By combining (57) and (59), we can write the following expressions for second period asset holdings

$$
\begin{aligned}
I_{2}^{T B}(s) & =\frac{P_{2}^{T B}(r) \bar{V} R^{T B} D^{T B}-\sigma_{l}\left(P_{2}^{T B}(s) I_{1}^{T B}(s)+P_{2}^{T B}(r) I_{1}^{T B}(r)+I_{1}^{T B}(\lambda)\right)}{P_{2}^{T B}(r)-\sigma_{l} P_{2}^{T B}(s)} \\
I_{2}^{T B}(r) & =\frac{P_{2}^{T B}(s)\left(I_{1}^{T B}(s)-\bar{V} R^{T B} D^{T B}\right)+P_{2}^{T B}(r) I_{1}^{T B}(r)+I_{1}^{T B}(\lambda)}{P_{2}^{T B}(r)-\sigma_{l} P_{2}^{T B}(s)}
\end{aligned}
$$

When there is a liquidity shortfall $\theta^{T B}<1$, we can use the expressions in Proposition 3 and (58) to write the problem as

$$
\begin{aligned}
E\left[\Pi^{T B}\right]= & (1-q)\left(\sigma_{h} I_{1}^{T B}(r)+I_{1}^{T B}(s)+I_{1}^{T B}(\lambda)\right) \\
& +\left[P_{2}^{T B}(s) I_{1}^{T B}(s)+P_{2}^{T B}(r) I_{1}^{T B}(r)+I_{1}^{T B}(\lambda)\right] *\left[q \xi \frac{1-q+q(1-p)(1-\xi)}{1-q}\right. \\
& \left.+q \frac{(1-p)(1-\xi)}{P_{2}^{T B}(r)-\sigma_{l} P_{2}^{T B}(s)}\left(\left(\sigma_{h}-\sigma_{l}\right)-\xi \frac{q(1-p)}{p(1-q)}\left(\sigma_{h} P_{2}^{T B}(s)-P_{2}^{T B}(r)\right)\right)\right] \\
& -(1-q+q(1-p)(1-\xi))\left(1+\frac{q}{1-q} \xi\right) D^{T B} \\
& -q(1-p)(1-\xi)\left(1-\xi \frac{q(1-p)}{p(1-q)}\right)\left(\frac{\sigma_{h} P_{2}^{T B}(s)-P_{2}^{T B}(r)}{P_{2}^{T B}(r)-\sigma_{l} P_{2}^{T B}(s)}\right) D^{T B}
\end{aligned}
$$

s.t.

$$
P_{1}^{T B}(\lambda) I_{1}^{T B}(\lambda)+P_{1}^{T B}(s) I_{1}^{T B}(s)+P_{1}^{T B}(r) I_{1}^{T B}(r)=D^{T B}
$$

which yields the first order conditions

$$
\begin{aligned}
P_{1}^{T B}(r) & =\frac{1}{1+\mu} \frac{(1-q) \sigma_{h}+\bar{Z}_{1} P_{2}^{T B}(r)}{\bar{Z}_{2}} \\
P_{1}^{T B}(s) & =\frac{1}{1+\mu} \frac{1-q+\bar{Z}_{1} P_{2}^{T B}(s)}{\bar{Z}_{2}} \\
P_{1}^{T B}(\lambda) & =\frac{1}{1+\mu} \frac{1-q+q \bar{Z}}{\bar{Z}_{2}}
\end{aligned}
$$


where

$$
\begin{aligned}
\bar{Z}_{1} \equiv & q \frac{\xi(1-q+q(1-p)(1-\xi))}{1-q} \\
& +\frac{q(1-p)(1-\xi)}{P_{2}^{T B}(r)-\sigma_{l} P_{2}^{T B}(s)}\left(\left(\sigma_{h}-\sigma_{l}\right)-\xi \frac{q(1-p)}{p(1-q)}\left(\sigma_{h} P_{2}^{T B}(s)-P_{2}^{T B}(r)\right)\right) \\
\bar{Z}_{2} \equiv & (1-q+q(1-p)(1-\xi))\left(1+\frac{q}{1-q} \xi\right) \\
& +q(1-p)(1-\xi)\left(1-\xi \frac{q(1-p)}{p(1-q)}\right)\left(\frac{\sigma_{h} P_{2}^{T B}(s)-P_{2}^{T B}(r)}{P_{2}^{T B}(r)-\sigma_{l} P_{2}^{T B}(s)}\right)
\end{aligned}
$$

When there is no liquidity shortfall $\theta^{T B}=1$, we can use $R^{T B}=\bar{V}=1$ from Proposition 3 to write the problem as

$$
\begin{aligned}
E\left[\Pi^{T B}\right]= & (1-q)\left(\sigma_{h} I_{1}^{T B}(r)+I_{1}^{T B}(s)+I_{1}^{T B}(\lambda)\right) \\
& +q(1-p)\left(\sigma_{h}-\sigma_{l}\right) \frac{P_{2}^{T B}(s) I_{1}^{T B}(s)+P_{2}^{T B}(r) I_{1}^{T B}(r)+I_{1}^{T B}(\lambda)}{P_{2}^{T B}(r)-\sigma_{l} P_{2}^{T B}(s)} \\
& -\left(q(1-p)\left(\frac{\sigma_{h} P_{2}^{T B}(s)-P_{2}^{T B}(r)}{P_{2}^{T B}(r)-\sigma_{l} P_{2}^{T B}(s)}\right)+(1-q p)\right) D^{T B}
\end{aligned}
$$

s.t.

$$
P_{1}^{T B}(\lambda) I_{1}^{T B}(\lambda)+P_{1}^{T B}(s) I_{1}^{T B}(s)+P_{1}^{T B}(r) I_{1}^{T B}(r)=D^{T B}
$$

The first order conditions FOCs then become

$$
\begin{aligned}
P_{1}^{T B}(r) & =\frac{1}{1+\mu} \frac{(1-q) \sigma_{h}\left(P_{2}^{T B}(r)-\sigma_{l} P_{2}^{T B}(s)\right)+q(1-p)\left(\sigma_{h}-\sigma_{l}\right) P_{2}^{T B}(r)}{(1-q) P_{2}^{T B}(r)+\left(q(1-p) \sigma_{h}-(1-q p) \sigma_{l}\right) P_{2}^{T B}(s)} \\
P_{1}^{T B}(s) & =\frac{1}{1+\mu} \frac{(1-q)\left(P_{2}^{T B}(r)-\sigma_{l} P_{2}^{T B}(s)\right)+q(1-p)\left(\sigma_{h}-\sigma_{l}\right) P_{2}^{T B}(s)}{(1-q) P_{2}^{T B}(r)+\left(q(1-p) \sigma_{h}-(1-q p) \sigma_{l}\right) P_{2}^{T B}(s)} \\
P_{1}^{T B}(\lambda) & =\frac{1}{1+\mu} \frac{(1-q)\left(P_{2}^{T B}(r)-\sigma_{l} P_{2}^{T B}(s)\right)+q(1-p)\left(\sigma_{h}-\sigma_{l}\right)}{(1-q) P_{2}^{T B}(r)+\left(q(1-p) \sigma_{h}-(1-q p) \sigma_{l}\right) P_{2}^{T B}(s)}
\end{aligned}
$$

\section{J Alternative specification for bank-runs}

Following the global games solution of Goldstein and Pauzner (2005), we postulate that banks with a shortfall of liquidity are more vulnerable to bank-runs. Specifically, we depict the probability $\xi$ that a bank faces a self-fulfilling run as a negative function $\zeta($.$) of its liquidation$ value $\theta$ such that

$$
\begin{gathered}
\xi=\zeta(\theta), \\
\zeta^{\prime}(.) \leq 0, \zeta(\theta) \in[0,1] \forall \theta
\end{gathered}
$$


Figure 14: Results under alternative bank-run specification
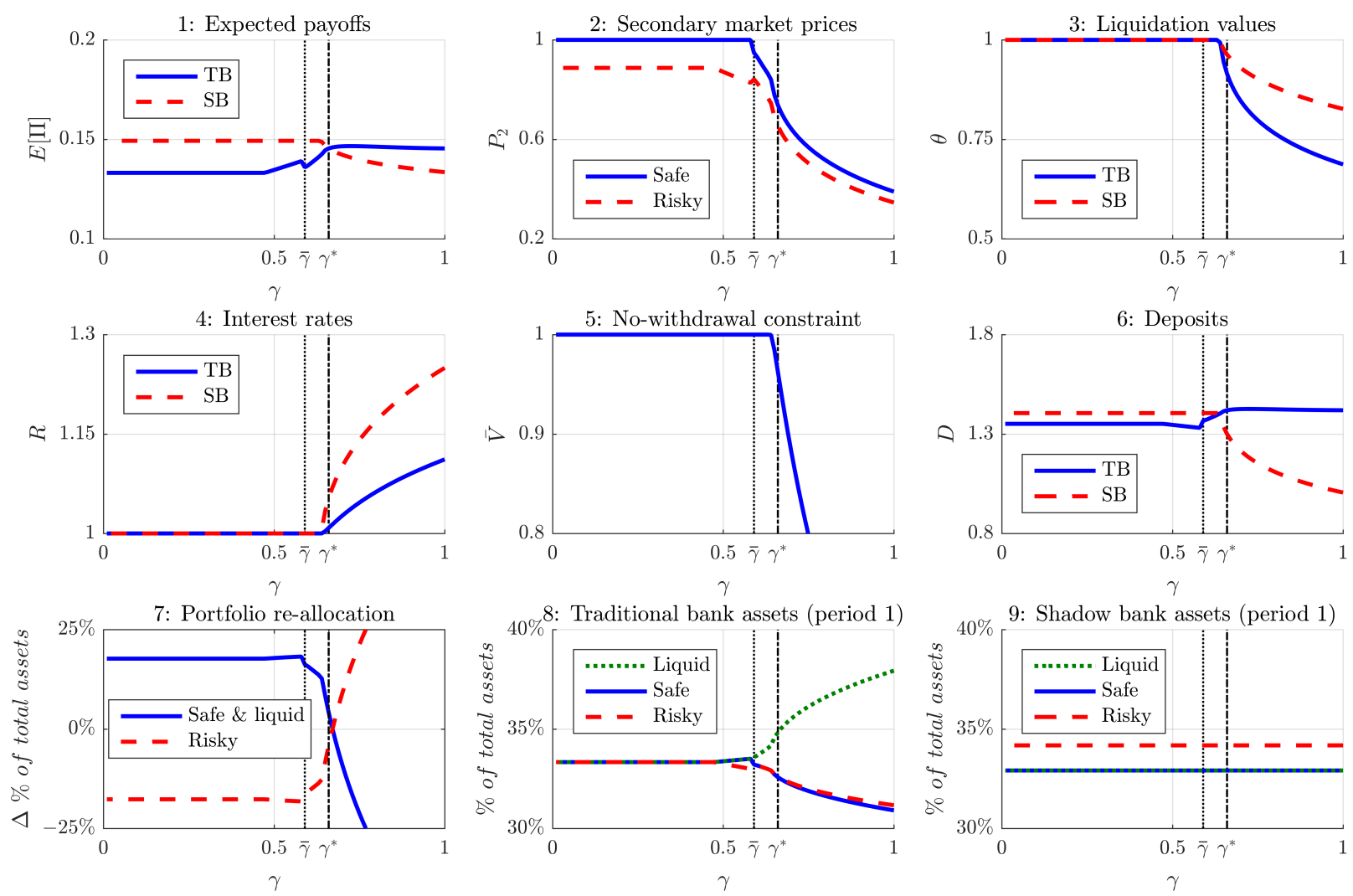

Note: Expected payoffs are inclusive of the commitment cost $\tau$. Total assets in period 1 and 2 are respectively defined as $\bar{I}_{1} \equiv \sum_{i \in\{\lambda, s, r\}} I_{1}(i)$ and $\bar{I}_{2} \equiv \sum_{i \in\{s, r\}} P_{2}(i) I_{2}(i)$. Panel 7 plots $\left(\bar{I}_{2}^{T B}\right)^{-1} P_{2}(s) I_{2}^{T B}(s)-$ $\left(\bar{I}_{1}^{T B}\right)^{-1} \sum_{i \in\{\lambda, s\}} I_{1}^{T B}(i)$ for safe and liquid assets, and $\left(\bar{I}_{2}^{T B}\right)^{-1} P_{2}(r) I_{2}^{T B}(r)-\left(\bar{I}_{1}^{T B}\right)^{-1} I_{1}^{T B}(r)$ for risky assets. Panel 8 plots $I_{1}^{T B}(i) / \bar{I}_{1}$ respectively for $i=\{\lambda, s, r\}$ and Panel 9 does the same for shadow banks.

where $\zeta(1)=0$ ensures that banks without a liquidity shortfall are not vulnerable to selffulfilling runs. ${ }^{45}$ We parameterize $\zeta($.$) simply as$

$$
\zeta(\theta)=\max \{0, \min \{1, \widetilde{\xi}(1-\theta)\}\}
$$

with $\widetilde{\xi}=1.64$ calibrated in line with the calibration strategy described in Section 5.1. Figure 14 provides the numerical results under a set up and calibration that are otherwise identical to those presented in Section 5.2. In equilibrium, the two bank run specifications yield exactly the same set outcome. At above equilibrium sizes of shadow banking $\left(\gamma>\gamma^{*}\right)$, the alternative bank run specification implies further increases in $\xi$ in line with the decrease in liquidity. This leads to lower traditional bank profits and a sharper decline in minimum recovery rate $\bar{V}$ compared to the baseline case.

\footnotetext{
${ }^{45}$ We also impose $\psi(\theta) \in[0,1] \forall \theta$ since $\xi$ is a probability.
} 